Review

\title{
The Roles of Noncardiomyocytes in Cardiac Remodeling
}

\author{
Dan Yang1,2,3*, Han-Qing Liu ${ }^{4^{*}}$, Fang-Yuan Liu1,2,3, Nan Tang 1,2,3, Zhen Guo ${ }^{1,2,3}$, Shu-Qing Ma1,2,3, Peng \\ An ${ }^{1,2,3}$, Ming-Yu Wang ${ }^{1,2,3}$, Hai-Ming Wu ${ }^{1,2,3}$, Zheng Yang1,2,3, Di Fan ${ }^{1,2,3}$ and Qi-Zhu Tang 1,2,3凶 \\ 1. Department of Cardiology, Renmin Hospital of Wuhan University, Wuhan 430060, RP China. \\ 2. Cardiovascular Research Institute of Wuhan University, Wuhan 430060, RP China. \\ 3. Hubei Key Laboratory of Metabolic and Chronic Diseases, Wuhan 430060, RP China. \\ 4. Department of Thyroid and Breast, Renmin Hospital of Wuhan University, Wuhan 430060, RP China. \\ *These authors contributed equally to this work.
}

$\square$ Corresponding authors: Department of Cardiology, Renmin Hospital of Wuhan University, Cardiovascular Research Institute, Wuhan University at Jiefang Road 238, Wuhan 430060, RP China. Qi-Zhu Tang, Tel.: +86 27 88073385; Fax: +86 27 88042292; E-mail: qztang@whu.edu.cn. Di Fan, Tel.: +86 27 88041911; E-mail: drfanti@yeah.net.

(1) The author(s). This is an open access article distributed under the terms of the Creative Commons Attribution License (https://creativecommons.org/licenses/by/4.0/). See http://ivyspring.com/terms for full terms and conditions.

Received: 2020.04.19; Accepted: 2020.06.16; Published: 2020.07.02

\begin{abstract}
Cardiac remodeling is a common characteristic of almost all forms of heart disease, including cardiac infarction, valvular diseases, hypertension, arrhythmia, dilated cardiomyopathy and other conditions. It is not merely a simple outcome induced by an increase in the workload of cardiomyocytes (CMs). The remodeling process is accompanied by abnormalities of cardiac structure as well as disturbance of cardiac function, and emerging evidence suggests that a wide range of cells in the heart participate in the initiation and development of cardiac remodeling. Other than CMs, there are numerous noncardiomyocytes (non-CMs) that regulate the process of cardiac remodeling, such as cardiac fibroblasts and immune cells (including macrophages, lymphocytes, neutrophils, and mast cells). In this review, we summarize recent knowledge regarding the definition and significant effects of various non-CMs in the pathogenesis of cardiac remodeling, with a particular emphasis on the involved signaling mechanisms. In addition, we discuss the properties of non-CMs, which serve as targets of many cardiovascular drugs that reduce adverse cardiac remodeling.
\end{abstract}

Key words: cardiac remodeling; noncardiomyocytes; cardiac fibroblast; immune cells

\section{Introduction}

Cardiac remodeling refers to structural and functional abnormalities of the heart (mainly left ventricular, LV) that develop in response to various internal or external pathological stimuli. Cardiac remodeling often causes changes in the wall thickness, ventricular volumes and cardiac mass, which further leads to reduced ventricular ejection and imbalances in the neurohumoral system, this, in turn, aggravates ventricular remodeling and ultimately causes noncompensatory heart failure (HF). Cardiac remodeling is a remarkable pathogenic manifestation of many serious cardiovascular diseases that ultimately progress to HF [1-5]. Studies have shown that structural, electrical and energetic remodeling are involved in this progression, among which the former two play a leading role [6]. Cardiac remodeling is closely related to the prognosis of clinical $\mathrm{HF}$ and has become an important therapeutic target for HF [7].

The heart is a complex multicellular tissue consisting of a heterogeneous population of $\mathrm{CMs}$ and morphologically and functionally distinct non-CMs (including fibroblasts, immune cells, pericytes and endothelial cells), with CMs accounting for approximately $22.8 \%$ of the total population and nonCMs accounting for the rest [8]. Cardiac remodeling is well regulated by cell apoptosis, proliferation, migration and differentiation in cardiac or extracardiac tissues. A recently published transcriptome profiling study of 21422 single cells 
collected from normal and failing heart samples revealed the important roles of non-CMs in regulating the behavior of CMs [9]. Numerous studies have reported that non-CMs contribute to various heart diseases, cardiac regeneration and the initiation and development of cardiac remodeling $[10,11]$.

This review summarizes the current understanding of the involvement of non-CMs in the pathogenesis of cardiac remodeling, with a particular emphasis on the potentially involved regulatory factors and signaling mechanisms. In addition, the properties of non-CMs are discussed, since they are important targets of many cardiovascular drugs that alleviate adverse cardiac remodeling.

\section{Cardiac fibroblasts}

The adult mammalian heart is enriched in fibroblasts. Cardiac fibroblasts (CFs) account for approximately $27 \%, 64 \%$, and $72 \%$ of the heart mass in mice, rats and humans, respectively [12]. Previous studies have shown that CFs are a significant cellular effector involved in cardiac remodeling, especially in the regulation of cardiac fibrosis. When exposed to pressure/volume overload or other pathological stimuli, CFs will differentiate into myofibroblasts, which can produce large amounts of extracellular matrix (ECM) proteins. However, the significance of $\mathrm{CF}$ extends far beyond regulating the production of ECM. Instead, CFs play a critical role not only in maintaining structural integrity and systolic function of the infarcted zones via the formation of matrix components within a relatively short time, but also in causing abundant collagen deposition and cardiac fibrosis due to their constant response to pathophysiological stimuli. In the past, due to the lack of CF-specific markers, many facts about CF biology remained controversial. With the generation of genetic mouse models that express the CF-specific Cre recombinase [13-15], it is possible to know more about this cell type.

\section{Origins of cardiac fibroblasts}

There are several major sources of $\mathrm{CFs}$, among which resident $\mathrm{CFs}$ remain the predominant source. Experiments using genetic lineage tracing approaches have shown that the resident fibroblast lineage was derived from epicardium-derived progenitor cells (EPDCs) undergoing epithelial-to-mesenchymal transition (EMT) during embryonic development [16]. During the development of the heart, EPDCs migrate to the myocardium and are trapped in the interstitium of the myocardium and finally become resident CFs. During EPDC mobilization, the cooperation of myocardin-related transcription factor (MRTF) and serum response factor (SRF) via the MRTF-SRF axis is required [17]. Another study performed with fluorescence-based genetic lineage tracing technology revealed that the post-MI scar principally collected epicardium-derived myofibroblasts, which could be specifically ameliorated by deletion of the Mrtf or Srf genes, indicating that resident CFs mainly originate from the epicardium under pathological conditions [18]. Additionally, it has been reported that a small fraction of CFs residing in the heart have an endothelial origin $[19,20]$. Epithelial- and endothelialderived cells altogether contribute to the formation of resident CFs. Interestingly, after undergoing pressure overload injury, CFs from different embryonic sources exhibited almost the same phenotypes and gene expression modes, suggesting the possibility that CF proliferation is affected by the cellular microenvironment instead of the developmental origins [19].

In addition to resident $\mathrm{CFs}$, some other extracardiac cell sources are contributors to the expanding myofibroblast population in the remodeled heart. These include endothelial cells, pericytes and bone marrow-derived cells (BMCs). Endothelial cells undergoing endothelialmesenchymal transition (EndMT) eventually transform into $\mathrm{CFs}$, the process of which can be induced by transforming growth factor-beta 1 (TGF$\beta 1$ ) and blocked by bone morphogenic protein 7 (BMP-7) [21]. Moreover, Gli1-positive perivascular MSC-like cells proliferated after heart injury, and depletion of these cells protected against postinfarct remodeling [22]. Investigators also found $\mathrm{CD} 45^{+}$/ eGFP $^{+}$inflammatory cells [23] and monocyte-derived myofibroblasts [24] in the infarcted heart. Furthermore, in a cardiac fibrosis rat model induced by angiotensin II (Ang II) infusion, bone marrowderived monocytes were found to differentiate into myofibroblasts, which involved the interaction of the $\mathrm{K}_{\mathrm{Ca}} 3.1$ and TRPV4/TRPC6 channels [25]. Additionally, cardiac macrophages were tracked in LysM $\left(\mathrm{Cre}^{/+}\right) ; \mathrm{ROSA}_{26}\left(\mathrm{EYFP}^{/+}\right)$transgenic mice undergoing MI surgery, and both in vivo and in vitro experiments indicated that macrophages were capable of differentiating into a fibroblast-like phenotype during myocardial healing after MI [26]. Therefore, CFs are a cell type with multiple sources, among which resident $\mathrm{CFs}$ account for the majority of CFs, and BMC-, epithelial-, endothelial- and pericyte-derived $\mathrm{CFs}$ are also valuable (Figure 1).

\section{Mechanisms underlying CF activation in cardiac remodeling}

It is widely acknowledged that CF is a key mediator that regulates the integrity and function of infarcted heart tissues by secreting ECM and some 
regulatory factors, and a variety of signaling pathways are involved. Many of the latest studies have revealed new insights into the regulatory roles of CFs.

CF activation is an extremely complex biological process. The data obtained from CF stage-specific lineage tracing provided an in-depth understanding of the differentiation states and dynamics of CFs in the process of scar formation following MI. Resident CFs in infarcted regions usually progressed through the following three stages: in the early stage (within 2-4 days), CFs were maximally activated and expanded in number by 3.5 -fold; in the middle stage (days 4-7), CFs differentiated into myofibroblasts that secreted large amounts of ECM to maintain the integrity of the heart tissue; and finally (by day 10), these cells gradually lost the ability to proliferate and produce a-SMA and ultimately turned into matrifibrocytes during scar maturing [27].

Additional evidence from current studies has shown that a range of genes, molecules, and even cellular structures are involved in CF proliferation and activation in response to physiological and pathological factors [28-32] (Figure 1).

Recent research utilized two- and threedimensional (2D vs 3D) culture conditions to study the topological arrangement of $\mathrm{CF}$ after heart injury, and the authors found that the recruitment, proliferation, and aggravation of CFs to the injured area induced gene expression changes, chromatin remodeling, and altered phenotypic features during the healing of injury [31].

It has been well established that many ion channels are important mediators of CF activation, among which $\mathrm{Ca}^{2+}$ channels are of great importance [33-35]. $\mathrm{K}_{\mathrm{Ca}} 3.1$ channels facilitated cardiac remodeling mainly by exacerbating cardiac fibrosis as well as inflammation; $\mathrm{K}_{\mathrm{Ca}} 3.1$ channels promoted the secretion of interleukin-4 (IL-4) and IL-13, both of which upregulated the differentiation of bone marrowderived monocytes into fibrocytes, which are cells that mature into fibroblasts and eventually myofibroblasts; $\mathrm{K}_{\mathrm{Ca}} 3.1$ channels accelerated the infiltration and differentiation into macrophages of monocytes, which further induced inflammation in the heart [25]. Another very recent study provided evidence that Piezo 1, a $\mathrm{Ca}^{2+}$-permeable ion channel, was highly expressed and played key roles in murine and human CFs. The mechanical activation of Piezo1 channels was specifically induced by Yoda 1, and then IL-6 expression was enhanced via the p38 mitogenactivated protein kinase (MAPK) pathway [30]. The MAPK signaling pathway is another effector, of great pathophysiological importance, for the migration, proliferation and differentiation of CFs. MAP kinase-activated protein kinase 5 (MK5) is a protein

\section{Origins of $\mathrm{CFs}$}

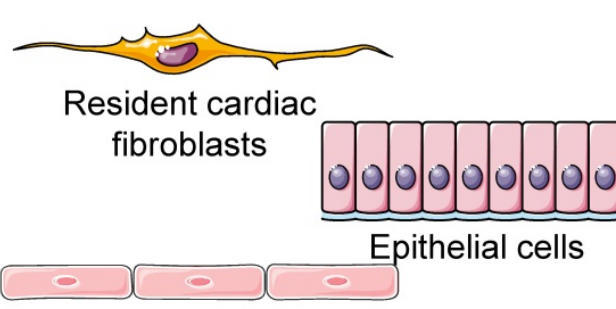

Endothelial cells

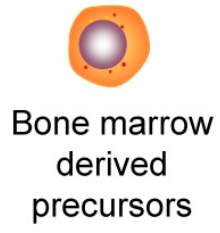

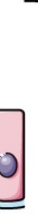
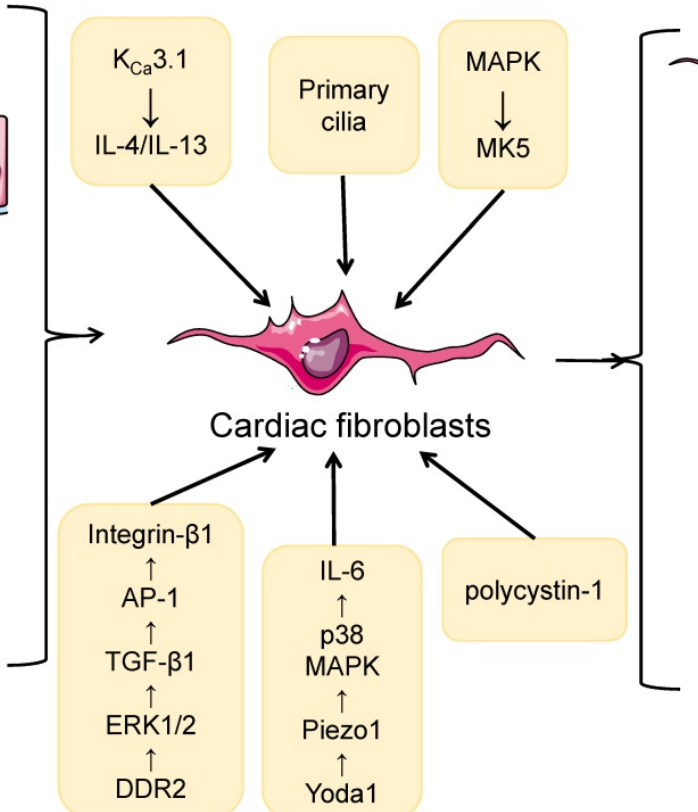

Activation of $\mathrm{CFs}$

\section{Potential mechanisms}

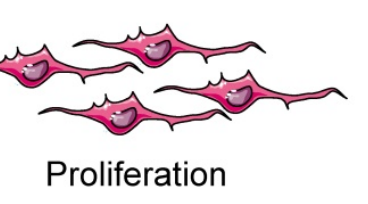

\section{Differentiation}

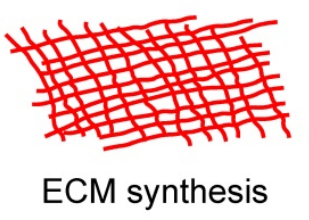

Figure 1. Summary of the origins as well as the activation of cardiac fibroblasts (CFs). CFs have several sources, including resident cardiac fibroblasts, epithelial cells, endothelial cells, pericytes, and bone marrow-derived cells. When exposed to pressure/volume-overload or other pathological stimuli, CFs will undergo proliferation as well as differentiation into myofibroblasts, cells that can produce large amounts of extracellular matrix (ECM) proteins and directly contribute to cardiac fibrosis. In addition, a lot of potential mechanisms are involved in this process. 
serine/threonine kinase that is activated by both the $\mathrm{p} 38 \mathrm{a} / \beta$ MAPKs and the atypical MAPKs ERK3 and ERK4. CFs isolated from $\mathrm{MK}^{-/-}$and $\mathrm{MK}^{+/-}$mice exhibited decreased secretion of type 1 collagen and fibronectin compared with those isolated from $\mathrm{MK}^{+/+}$mice, while MK5-deficient fibroblasts were showed reduced contraction [32]. Recently, studies have also indicated the role of collagen receptor cross-talk in cardiac remodeling: cross-talk between DDR2 and Integrin- $\beta 1$ influences collagen type I and a-SMA expression in Ang II-stimulated $\mathrm{CFs}$ via ERK1/ 2 MAPK-dependent TGF- $\beta 1$ signaling [28].

Cellular structures can also modulate the cardiac remodeling process. In injured myocardium stimulated by disease-related stress, a cellular microstructure named the primary cilium, which is harbored in CFs from both neonatal and adult hearts, was first discovered. Primary cilia along with polycystin-1 (PC1) were first recognized as crucial regulators of TGF- $\beta 1$-induced cardiac fibrogenesis. PC1 knockdown in myofibroblasts significantly increased adverse cardiac remodeling following MI [29]. Taken together, the results of these studies suggest that CFs modulate cardiac remodeling at various levels via cells, proteins and genes. Importantly, an in-depth investigation is required to systematically reveal the effects of CFs.

\section{Therapies targeting CFs}

Since the mechanisms involved in CF activation have already been demonstrated, therapies targeting CFs seem to be promising, and their implementation has progressed from the bench to the bedside. A very recent study demonstrated PET imaging of activated CFs by utilizing a ${ }^{68} \mathrm{Ga}$-labeled fibroblast activation protein (FAP) inhibitor ( $\left.{ }^{68} \mathrm{Ga}-\mathrm{FAPI}-04\right)$, which was a noninvasive and repeatable technique that provided new insights into the diagnosis and prognosis of heart diseases (such as post-MI syndrome, cardiac fibrosis, hypertension, $\mathrm{HF}$, and other conditions) related to $\mathrm{CF}$ activation [36]. Revascularization of the affected cardiac tissue appears to be a promising strategy to attenuate the effects of adverse cardiac remodeling. Delivery of growth factors (VEGF, PDGF, and bFGF) into injured heart tissue has increasingly been used [37, 38]. However, challenges related to low efficacy, a high loss rate and low retention remain to be solved. A newly constructed bFGF release system with adequate release kinetics may solve these problems. A bFGF-encapsulating hydrogel not only served as a drug carrier, but also effectively preserved fibroblast phenotypes so that the pro-angiogenesis and anti-fibrotic functions of CFs were maintained [39]. Additionally, some cardioprotective molecules associated with $\mathrm{CFs}$ have been discovered, for example, a novel agent, NM922, of therapeutic value could inhibit the conversion of the CF phenotype in a murine TAC model by preventing the activation of several profibrotic pathways (including pathways involving mTOR/STAT3/E4-BP1, FAK-Akt-P70S6K, and the generation of COX-2) [40]. Administration of sacubitril/valsartan (SAC/VAL) appears to be a promising strategy to improve pressure overloadinduced cardiac fibrosis by directly acting on fibroblasts. The positive effect of SAC/VAL is mediated by the restoration of protein kinase $G$ (PKG) signaling in CFs [41]. In addition, exchange protein activated by cyclic AMP 1 (EPAC1), a signaling molecule activated by adrenergic stimulation, was downregulated in CFs from atrial fibrosis hearts. Overexpression of EPAC1-signaling seemed to be cardioprotective [42]. Delivery of ECM biomaterials is another effective strategy to promote cardiac regeneration and maintain heart function recovery [43]. Direct cardiac reprogramming offers a potential novel approach for restoring cardiac function, during which CFs could be converted into induced CM-like cells (iCMs) without first reverting them into stem cells [44]. Direct cardiac reprogramming can be achieved by the transduction of various cardiacspecific factors [45]. A large number of studies have discovered the effectiveness of the direct reprogramming of murine $\mathrm{CFs}$ into $\mathrm{iCMs}$ in vitro [46-50]. Importantly, Nam et al. [51] have successfully determined the optimal combination of cardiac transcription factors required to direct the reprogramming of human $\mathrm{CFs}$, including Hand2, GATA4, T-box5, myocardin, miR-1 and miR-133; afterward, the stimulated CFs can be directly reprogrammed to become CMs after the induction of the expression of these proteins and microRNAs, and these human CFs exhibited sarcomere-like structures and calcium transients along with expression of cardiac genes. A recent in vitro/vivo study revealed that a combination of TGF- $\beta$ and WNT inhibitors markedly enhanced the efficiency of GMT (Gata4, Mef2c, and Tbx5)-induced direct cardiac reprogramming, providing robust evidence of the possibility for cardiac regeneration [52].

In summary, therapies for cardiac remodeling by the direct/indirect targeting of $\mathrm{CFs}$ via known signaling pathways and molecular mechanisms of CFs are emerging rapidly. The efficacy and safety of these potential therapies require further clinical investigations.

\section{Immune cells}

Immune cells are important parts of the innate immune system of mammals. Research has indicated that acute inflammatory signals stimulate the cardiac 
regenerative response in neonatal mice [53]. Numerous experimental studies have found that the immune response in injured heart tissue helps regulate $\mathrm{CM}$ function and induce adverse cardiac remodeling [54-56]. The important roles of inflammatory cells, innate immune molecules and the reprogramming of relevant signaling pathways in cardiac remodeling following ischemic heart diseases were reviewed previously [57-59]. In this section, we will summarize the very recent advances in the understanding of the effects of heterogeneous populations of immune cells (including macrophages, neutrophils, lymphocytes and mast cells) and regulatory mechanisms on the development of cardiac remodeling.

\section{Cardiac Macrophages}

Macrophages are found in almost all types of tissues. Cardiac macrophage, as an important part of the mononuclear phagocyte system, constitutes approximately $7 \%$ of the nonmyocytes in the adult mouse heart [60]. Cardiac macrophages are mainly derived from blood-derived monocytes and the yolk sac (YS) [61]. Of the two sources, a growing body of studies has paid more attention to monocytemacrophage transition because of its universality, heterogeneity and complexity. Immature cells in the bone marrow are regarded as significant contributors to blood-circulating monocytes, which constantly migrate to the peripheral tissues, where they differentiate into macrophages [62]. Monocytes and macrophages are intimately related in terms of their sources as well as their functions and serve as critical contributors to the innate immune response to inflammation.

\section{Heterogeneity of cardiac monocytes and macrophages}

Monocytes usually originate from myeloid progenitors in the bone marrow. In mice, monocytes are classified into two subsets, the classical Ly-6Chigh CCR2 ${ }^{\text {high }}$ CX3CR1 $1^{\text {low }}$ and nonclassical Ly6ClowCCR2 ${ }^{\text {low } C X 3 C R 1 ~} 1^{\text {high }}$ subtypes, based on Ly-6C expression levels; the former subtype migrates to the infarcted areas and serves as the main contributor to inflammation, while the latter always persists in the circulation and is responsible for maladaptive remodeling [63-65].

In cardiac macrophages, the expression of CCR2 (chemokine receptor type 2, a receptor of CCL2/ MCP1 and CCL7/MCP3) greatly influences cellular behaviors. Both inflammatory monocyte-derived $\mathrm{CCR}^{+}$and tissue-resident CCR2- macrophages are present in mouse hearts. Tissue-resident macrophages (TRMs) are a group of cells that take residence in various tissues (including the heart, gut, and dermis) prior to birth and maintain themselves locally throughout adulthood by performing immune hemostatic and sentinel functions [66, 67]. TRMs originate from a transient hematopoietic wave of erythromyeloid progenitors that emerge from the YS, and importantly, TRMs can also be continuously repopulated through self-renewal, completely or partially independent of bone marrow contributions $[67,68]$. CCR2-positive macrophages could recruit monocytes in an MYD88 (myeloid differentiation primary response 88)-dependent manner, and MYD88, as a key mediator, could further lead to the release of MCPs (monocyte chemoattractant proteins) and the migration of monocytes to the infarcted zone. Selective removal of $\mathrm{CCR}^{+}$or CCR2- macrophages before $\mathrm{MI}$ had conflicting results with regard to monocyte recruitment, LV function and remodeling [69]. Similarly, a recent investigation of macrophage heterogeneity in the human heart suggested that the human heart contained distinct subsets of CCR2 ${ }^{+}$and CCR2 - macrophages. The two subtypes had different origins, localizations, and functions. CCR2macrophages, which developed during the embryonic stages, tended to appear in viable myocardium and had the potential to orchestrate tissue repair, whereas $\mathrm{CCR}^{+}{ }^{+}$macrophages, which originated from monocytes, preferred to remain in fibrotic sites and were related to inflammation [70]. Another discovery regarding cardiac macrophage heterogeneity was reported by Sarah A Dick and colleagues: by utilizing genetic fate mapping and single-cell RNA sequencing (scRNA-seq), the group discovered that healthy hearts contained four kinds of macrophages, TIMD4 ${ }^{+}$LYVE1 $^{+}$MHC-II $^{\text {loCCR2- }}$, $\quad$ TIMD4-LYVE1 ${ }^{-}$ MHC-II ${ }^{\text {hiCCR2- }}{ }^{-}$, and two CCR2 ${ }^{+} \mathrm{MHC}-\mathrm{II}^{\text {hi }}$ subsets of macrophages, which were independently, partially, and fully renewed by monocytes, respectively. Diversification of these subgroups occurred immediately after MI. The TIMD4 ${ }^{+}$and TIMD4subgroups were reduced in the early phase post MI but gradually increased via self-renewal [71]. ${ }^{68} \mathrm{Ga}-$ DOTA-ECL1i, a PET radiotracer, could specifically bind to $\mathrm{CCR} 2^{+}$monocytes/macrophages, and the signal was correlated with CCR2 ${ }^{+}$abundance, which provided an effective molecular imaging method to noninvasively visualize the recruitment of monocytes and macrophages to the infarct heart [72].

In conclusion, these findings showed that macrophages are extremely heterogeneous cells present in both human and murine cardiac tissues. Cardiac macrophages can be broadly divided into two subpopulations: cardiac resident macrophages and monocyte-derived macrophages. Resident macrophages, derived from the YS and self-renewal, reside in the myocardium and contribute to the 
maintenance of the cardiac steady state. In contrast, infiltrating macrophages are continuously repopulated by blood-circulating monocytes in a CCR2-dependent manner after various pathological stimuli, and $\mathrm{CCR}^{+}$monocyte-derived macrophages are responsible for the inflammatory response to cardiac injuries. However, current knowledge of macrophage subsets is very limited, and a more well-resolved and nuanced understanding of these cells will enable the targeting of disease-promoting macrophage functions.

\section{Activation and polarization of macrophages in cardiac remodeling}

Macrophages, which are equipped with various signaling receptors, are a crucial cell type that integrates signaling pathways and actively responds to disease-related stress. In healthy hearts, a group of macrophages of both YS and monocyte origin were present [66, 73]. In cardiac tissue undergoing infarction, the cellular response differed in different regions. At the site of MI, due to the destruction of resident cells, large numbers of circulating monocytes quickly entered the myocardium and transformed into macrophages, while in the peri-infarct zones, the continuous proliferation of TRMs and monocyte infiltration were both beneficial to the rapid expansion of macrophages; in the remote regions, macrophage populations were supplemented by monocyte recruitment rather than by TRMs [61, 63]. Importantly, macrophages residing in the pericardial space near the site of injury displayed cardioprotective functions. A study reported that a large number of $\mathrm{Gata6}^{+}$pericardial cavity macrophages (GPCMs) invaded the pericardial cavity in experimental MI mice. During the progression of remodeling, GPCMs lost the ability to express Gata6 and surprisingly exhibited antifibrotic effects. In line with these findings, depletion of the GPCMs or removal of the pericardial cavity led to a reduction in post MI cardiac remodeling. In addition, GPCMs were found in the pericardial fluid in humans, suggesting that they could be targeted by novel therapies for various heart diseases [74].

It is well established that the function of cardiac macrophages is largely dependent on the two subpopulations, comprising pro-inflammatory M1 and reparative M2 macrophages [75]. Ly6Chi M1 macrophages were characterized by the secretion of TNF- $\alpha$, IL-1 $\beta$, and IL-6, which are pro-inflammatory cytokines that contribute to the acute inflammatory response. In contrast, $\mathrm{Ly} 6 \mathrm{C}^{\text {lo }} \mathrm{M} 2$ macrophages express and release anti-inflammatory cytokines such as VEGF and TGF- $\beta$, contributing to CF activation, angiogenesis and wound healing [76]. In addition, infusion of IL-10 in vivo significantly increased the expression of M2 marker genes along with CF activation (as evidenced by CF proliferation, recruitment and ECM accumulation), and ultimately led to the improvement of cardiac remodeling both structurally and functionally [77]. A recent study using flow cytometry and RNA sequencing technology successfully mapped the transcriptomes of polarized macrophage during the first week post MI [78]: within the first day post MI, macrophages showed the unique features of pro-inflammatory proprieties and ECM degradation, while the macrophages on day 3 displayed the upregulation of proliferation and phagocytosis as well as the reprogramming of metabolism; macrophages on days 7 exhibited proreparative signatures characterized by the elevation of Col1a1, Col3a1, and postn expression. These data demonstrate the immediate responses and continuous trans-differentiation of the phenotypes of macrophage from an inflammatory M1 phenotype to a reparative $\mathrm{M} 2$ phenotype post $\mathrm{MI}$ and during tissue remodeling. In conclusion, cardiac macrophages play leading roles in regulating heart remodeling and show dynamic spatial and temporal changes. Figure 2 illustrates the activation process of cardiac macrophages.

\section{Potential therapies targeting macrophages}

Preclinical research has revealed a possible diagnostic macrophage biomarker, the scavenger receptor stabilin-1. Stabilin-1 ${ }^{+}$macrophages accumulated and peaked in number in the regenerative phase in both infarct and peri-infarct sites and remained unchanged in the late stage [79]. Moreover, many recent studies have suggested potential treatments for cardiac remodeling that target macrophage polarization. Long-term administration of eicosapentaenoic acid (EPA), which is known to reduce the incidence of nonfatal coronary diseases, especially reduced remodeling by inhibiting macrophage polarization towards an M1 phenotype [80]. Aminooxyacetic acid (AOAA) remains another novel agent. Short-term administration of AOAA led to a decreased proportion of M1 macrophages, an elevated proportion of M2 macrophages, and inactivation of the NLRP3-caspase1/IL-1 beta pathway [81]. In addition, some other agents such as hemin-carried drugs based on lipid [82], NADPH oxidase 4 (Nox4) [83], hyaluronic acid oligosaccharides (o-HA) [84], played possible beneficial roles in restoring cardiac function post MI by targeting cardiac macrophages and skewing them towards an M2 anti-inflammatory phenotype, which provided a novel strategy to regulate inflammation, reduce adverse remodeling, and improve the 
contractile function of infarcted hearts. Interestingly, some commonly used hypoglycemic drugs had certain effects in ameliorating cardiac remodeling. By modulating M2 polarization and preventing myofibroblast infiltration, the selective SGLT2 inhibitor dapagliflozin attenuated post MI remodeling in rats [85]. Similarly, in preclinical animal experiments, evidence has shown that nanoparticle (NP)-based agent pioglitazone is a potential antagonist of cardiac remodeling. The NPs were delivered specifically to cardiac monocytes/ macrophages, reducing the recruitment of macrophages and promoting the polarization of macrophages to the M2 phenotype [86]. Interestingly, a recent study revealed that stem cell therapy could dramatically improve cardiac function in mice after ischemia-reperfusion injury; mechanistically, cell therapy triggered an acute immune response characterized by temporal and regional accumulation of $\mathrm{CX}_{3} \mathrm{CR} 1^{+}$and $\mathrm{CCR}^{+}$macrophages [87]. Transplantation of murine neonatal macrophages has also been shown to be effective for adult cardiac repair [88]. Overall, given the biphasic response of cardiac macrophages to heart injuries, quite a few therapies targeting cardiac macrophages have been shown to be cardioprotective mainly by directly modifying macrophages or promoting macrophage phenotypic switching from a pro-inflammatory to an anti-inflammatory subtype.

\section{Neutrophils}

Neutrophils are the prominent leucocytes, accounting for approximately $50-70 \%$ of circulating leukocytes in humans and $10-25 \%$ in mice [89]. As an important component of the innate immune system, neutrophils act as a key player in cardiac remodeling induced by various external or internal stimuli.

\section{Activation of neutrophils in cardiac remodeling}

Neutrophils, which initiate the inflammatory reaction, were traditionally considered as "bad cells" post MI. Stimulated by cell debris, danger-associated molecular patterns (DAMPs) and cytokines from neighboring cells, a large number of neutrophils quickly migrate and accumulate in the injured areas a few hours after infarction, where they generate reactive oxygen species (ROS) and release granule contents, eventually causing acute tissue injuries [89, 90]. The elevation of neutrophils usually implies poor outcomes in patients suffering from acute coronary syndrome [91].

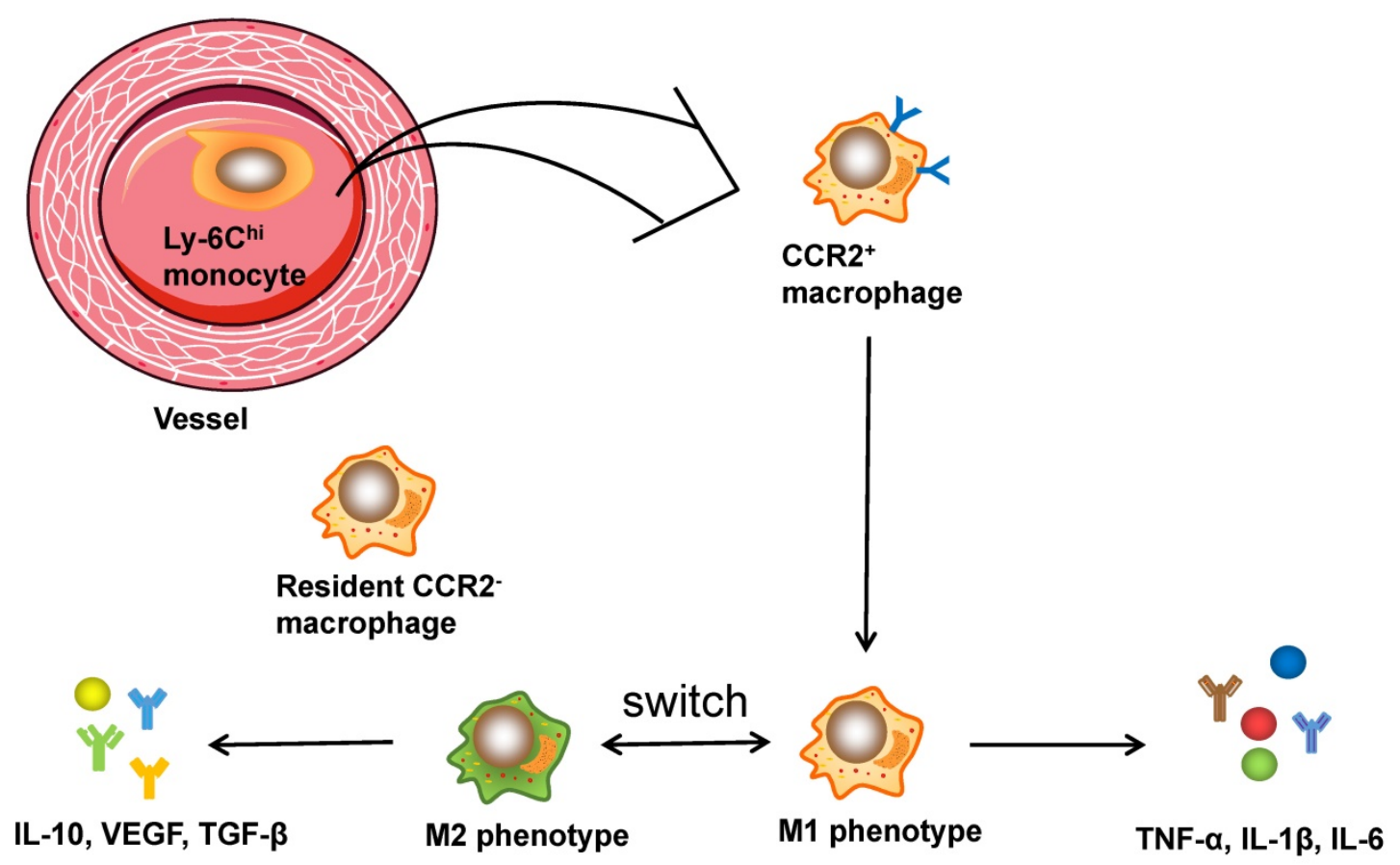

Pro-fibrotic response (late stage)

Pro-inflammatory response (early stage)

Figure 2. The activation of macrophages in cardiac injuries. CCR2 ${ }^{+}$macrophages, derived from circulating monocytes, have the potential to orchestrate the inflammatory phase and polarize into $\mathrm{Ml}$ and $\mathrm{M} 2$ phenotypes. Ly $6 \mathrm{Chi} \mathrm{M1}$ macrophages are characterized by secretion of TNF- $\alpha$, IL-1 $\beta$, and IL-6, which are pro-inflammatory cytokines that assist in acute inflammatory response, while Ly6Clo M2 macrophages express and release anti-inflammatory cytokines like VEGF and TGF- $\beta$, contributing to CF activation, angiogenesis and wound healing. Moreover, CCR2- macrophages, originating from embryo, reside in the myocardium and are related to fibrogenesis. 
Due to the improved understanding of neutrophils, it has been recently appreciated that neutrophils modulate cardiac remodeling through positive effects. Cardiac neutrophils also undergo polarization; as previously reported, they often consisted of the N1 (expressing CCL3, IL1 $\beta$, and $\mathrm{TNF} \alpha$ ) and N2 phenotypes (expressing IL10 and CD206) [92]. By performing aptamer proteomics, researchers have successfully mapped the polarization of cardiac neutrophils in coronary artery ligation-induced MI mouse models. Neutrophils on day 1 after MI were characterized by a high level of degranulation, the initiation of inflammation and the breakdown of ECM by activating matrix metalloproteinase (MMP); on days 3, the cells exhibited the upregulation of apoptotic signaling, cathepsin activity, and ECM reorganization; on day 5, neutrophils showed further reconstruction of the ECM and resolution of inflammation; and neutrophils on day 7 had typical reparative profiles, with high expression of galectin-3, fibronectin, and fibrinogen [93]. Therefore, it is apparent that neutrophils are extremely complex and capable of a variety of regulatory functions. The contributions of this cell type result from both its "pro-inflammatory" and "healing" effects.

\section{Important roles of NGAL}

Neutrophil gelatinase-associated lipocalin (NGAL), a kind of lipocalin first discovered in neutrophils and approved derived from various types of immune cells, remarkably increased in abundance within several days after MI as well as in clinical and experimental HF [94, 95]. NGAL blockade in vivo showed beneficial effects on limiting cardiac inflammation and fibrosis. The study also demonstrated that NGAL was mineralocorticoid receptor (MR)-dependent and exerted its pro-fibrotic roles in experimental MI and cardiac remodeling through the NF-kB signaling pathway [96]. In agreement with these results, NGAL was also found to be elevated in aldosterone-induced cardiac injuries, and the inhibition of NGAL led to anti-inflammatory and anti-fibrotic effects [97]. Moreover, clinical research has revealed the possibility of the use of NGAL as a supplementary marker for cardiovascular conditions [98]. Surprisingly, a recently published study announced the potential cardioprotective roles of neutrophils in cardiac healing, as evidenced by the excessive fibrosis, increased levels of markers for HF, and worsening cardiac function in neutrophildepleted mice; mechanistically, abundant neutrophils are required to recruit monocytes and promote macrophage polarization into the $\mathrm{M} 2$ reparative phenotype, which mainly occurs through the induction of NGAL [99]. In summary, these data indicate the pivotal effects of NGAL on the prognosis of patients with $\mathrm{HF}$ and the protective role of anti-NGAL strategies.

\section{Neutrophil signaling in cardiac remodeling}

Another interesting study indicated that neutrophil signaling post MI differed according to gender. Previous clinical investigations have found differences between men and women in terms of clinical manifestations and long-term prognosis after MI [100]. Through a combined analysis of retrospective, prospective and translational data, DeLeon-Pennell and coworkers convincingly revealed that sex differences existed in post MI inflammatory effects and wound healing. In neutrophils in males, PPARY (peroxisome proliferator-activated receptor $\gamma$ ) and LXR/RXR (liver $X$ receptor/retinoid $X$ receptor) served as the main contributors to immunosuppression; while in those in females, thrombospondin and LXR/RXR signaling played critical roles. In aging females, due to the inability to activate LXR/RXR signaling, a large amount of IL-6 and downstream signaling were activated, finally leading to the loss of protection [101]. These results provide evidence of sex-related differences in the treatment of male and female patients with cardiac remodeling.

\section{Lymphocytes}

Lymphocytes, which are an important subset of inflammatory cells, are roughly divided into T-lymphocytes and B-lymphocytes according to the organs where they differentiate, develop and mature. Both cell types participate in the modulation of cardiac remodeling [102-104]. Traditionally, CD4 ${ }^{+}$and $\mathrm{CD}^{+}$cells are two major categories of $\mathrm{T}$ cells that are identified by their cytokine secretion as well as their immune effects, and indeed, the former plays a predominant role in cardiac remodeling despite the etiology [105]. CD4 ${ }^{+}$cells consist of heterogeneous subsets, including INF- $\gamma$-producing T-helper (Th) 1 cells, IL-4-expressing Th2 cells, IL-17-positive Th17 cells and regulatory $\mathrm{T}$ cells (Tregs), among which the Th1 and Th17 subpopulations are pro-inflammatory, while Th2 and Tregs cells are anti-inflammatory [102].

\section{Engagement of T-lymphocytes in cardiac remodeling}

In heart tissue injured by pathological stimuli, cell debris and released antigens are delivered by dendritic cells (DCs) to T lymphocytes; subsequently, $\mathrm{T}$ cells become responsive to these pathogens and are broadly activated. Recruitment of $\mathrm{CD} 4^{+}$cells from the circulation to sites of injury requires sustained induction by cytokines, chemokines and adhesion molecules [106]. C-X-C motif chemokine ligand 12 
(CXCL12) and its receptor, CXCR4, are regarded as the main effectors mediating inflammatory cell recruitment and activation in injured tissues [107]; other molecular mediators include CXCL9, CXCL10, CXCL11, CXCR3, ICAM-1, and CCR5 [108]. Recently, published studies have revealed the remarkable expansion of both $\mathrm{CD}^{+}$and $\mathrm{CD} 8^{+} \mathrm{T}$-lymphocytes; the Th1, Th2, Th17, and Treg $\mathrm{CD}^{+}$subgroups were present in the circulation, HF myocardium, spleen and lymph nodes in murine models of ischemic HF, with the Th2 and Th17 subsets being predominant [109]. Consistent with these findings, T-cell infiltration was observed in peripheral blood and heart samples obtained from ischemic HF patients. By performing deep sequencing, researchers uncovered clonal expansion of the T-cell receptor repertoire in IHF, and these T cells were characterized by enhanced proliferation and memory- and effector-like properties [110].

Among various $\mathrm{T}$ cell types, Tregs expressing transcription factor forkhead box protein 3 (Foxp3) are a well-characterized $\mathrm{CD}^{+}{ }^{+}$subset that is typically immune-suppressive and helps maintain the stability of the immune system [111]. Correspondingly, Tregs had a positive influence on post MI healing, mainly during the transition from the inflammatory phase to the resolution phase [112]. Large numbers of $\mathrm{CD}^{+}{ }^{+} \mathrm{CD} 25^{+} \mathrm{Foxp}^{+}$Tregs were diffusely expanded and activated in the heart and other organs after ischemic cardiomyopathy [113, 114]. These "pathological" Tregs, which are different from those found in steady states, displayed pro-inflammatory properties (with the expression of TNFR1, TNFa and INF- $\gamma$ ) along with anti-angiogenetic and pro-fibrotic features. Selective ablation of these dysfunctional Tregs, interestingly, greatly alleviated cardiac fibrosis and hypertrophy, reversed remodeling and improved LV systolic function [115]. Hence, restoration of the normal features of Tregs remains the basis of maintaining "homeostatic" function. In conclusion, these findings indicate the significant effects of T cells on heart remodeling. Nevertheless, the details of $\mathrm{T}$ cell-specific antigens still need to be investigated. In addition, the respective roles of different subpopulations of $\mathrm{T}$ cells need to be identified.

\section{Engagement of B-lymphocytes in cardiac remodeling}

The roles of B lymphocytes in cardiac remodeling triggered by heart injury remained unrecognized for a long time. In Ang II-induced HF models, B-cell depletion exhibited cardioprotective effects, as evidenced by the significant reduction of cardiac hypertrophy and fibrosis, while B-cell reconstitution had the opposite effects [116]. After diphtheria toxin (DT)-induced acute heart injury or
I/ R injury, cytometry analysis revealed an increase in CD19+CD11b- B lymphocytes in comparison to that in naïve hearts, and further in vitro experiments demonstrated that the activation of B cells occurred in a TIRAP (Toll-interleukin 1 receptor-domain containing adaptor protein)-dependent manner [117]. However, since much is still unknown about B cells (including antibodies and subsets of B cells), effective agents to alleviate heart remodeling specifically by modulating B lymphocytes remain to be investigated.

\section{Potential treatments targeting lymphocytes}

Therapies that affect lymphocyte dynamics (recruitment, proliferation and activation) and relevant signaling are seemingly promising strategies. Experimental data revealed that a highly selective inhibitor of CXCR4 enhanced tissue healing and cardiac function after MI via cardiac mobilization of spleen-reserved $\mathrm{CD}^{+}{ }^{+} \mathrm{Foxp}^{+}$Tregs due to their specific immunoregulatory function [107]. In addition, due to an inadequate understanding of Treg clinical applications, therapies often focus on the indirect effects of this cell type. Tolerogenic dendritic cells (tDCs), a potential mediator of infarction healing, play therapeutic roles by modulating Tregs and M1/ M2 macrophage polarization [118]. Local intravenous injection of tDCs could improve the immune microenvironment, resulting in enhanced wound healing and improved survival after MI. Another newly declined immunotherapy using engineered $\mathrm{T}$ cells has provided novel insights into the treatment of cardiac fibrosis; cardiac injury and ovalbumin peptide (OVA) expression in CFs were induced by Ang II infusion and Cre recombinase administration, respectively. One week later, $\mathrm{CD} 8^{+} \mathrm{OT}-\mathrm{I} \mathrm{T}$ cells $\left(\mathrm{CD} 8^{+} \mathrm{T}\right.$ cells expressing a cognate $\mathrm{T}$ cell receptor against OVA) were transformed. The Postn $^{\mathrm{MCM}}$;RosaOVA mice that received modified $\mathrm{T}$ cells exhibited lower levels of fibrosis and remodeling [119]. Hence, applicable therapies are still limited, and methods of transforming "pathological" lymphocytes into normal lymphocytes and repressing the lymphocyte-specific inflammation are awaiting development.

\section{Mast Cells}

Mast cells (MCs), which are morphologically equipped with numerous cytoplasmic granules, are one of the most well-known cell types that are resident in almost all organs in response to allergy. In fact, MCs are multifunctional cells that participate in a large range of pathophysiologic processes in addition to allergic responses [120]. The function of MCs is dependent on various regulatory factors, including pro-allergic (histamine, TNF, and proteases), pro- 
inflammatory (INF- $\gamma$, IL-1 $\beta$ and IL-6), immunosuppressive (IL-10 and IL-13), pro-fibrotic (TGF- $\beta 1$ and bFGF) and anti-fibrotic (IL-33, VEGF and PGD2) mediators [120, 121]. Immediately after heart injury, MCs in the heart quickly responded to DAMPs and were significant mediators of cardiac remodeling. The regulation and dual roles of MCs in adverse myocardial remodeling have been reviewed by Scott P. et al. [122].

\section{Recent findings regarding MCs in cardiac remodeling}

Anta Ngkelo and colleagues have investigated the roles of MCs in LV remodeling. Flow cytometry/ imaging analysis revealed that MCs significantly expanded on day 7 after MI surgery, and MC-specific gene expression occurred in coordination with the release of typical granule contents. In the damaged heart, the infiltration of MC progenitors was observed. To further evaluate the function of MCs in infarcted myocardium, MC-deficiency mice were generated by Cre-mediated MC eradication $\left(\mathrm{Cpa} 3^{\mathrm{cre} /+}\right)$, and it was found that the contractile function of CMs (based on the LV wall thickness, LV postsystolic diameter, interventricular septal end-diastolic diameter, and shortening fraction) was decreased in MC-deficient mice compared to that in WT mice. In terms of the involved mechanism, the cardioprotective effects of MCs resulted from MC-mediated enhanced myofilament sensitization to $\mathrm{Ca}^{2+}[123]$. MCs are also involved in the progression of right ventricle (RV) remodeling. An increased number of MCs infiltrated and became activated in the RV tissue in mice generating pulmonary artery banding (PAB). The proportion of degranulated MCs started to increase at day 3 after PAB and peaked at D7; in contrast, the MC density began to increase at 2 weeks and reached a plateau by the third week after surgery. Notably, the levels of the MC marker c-Kit and MC-specific mMCP in RV were significantly elevated [124]. Thus, MCs may represent an evaluable target for new therapeutic approaches for both LV and RV remodeling.

Notably, among the granule contents released by MCs, chymase is one of the most important components. Among all mouse chymases (consisting of mouse mast cell protease- $1,-4,-5$, and -9 ), mouse mast cell protease- 4 (mMCP4) is most similar to that in humans [125]. An increasing number of studies have reported that $\mathrm{mMCP} 4$ participates in many CVDs and even HF. mMCP4 was extensively expressed in MCs post MI, and the deficiency of $\mathrm{mMCP} 4$ played a protective role in murine cardiac function after coronary artery ligation, which was characterized by reduced CM apoptosis, reduced accumulation of immune cells, impaired TGF- $\beta$ signaling, enhanced ECM degradation, and amelioration of the ejection fraction [126]. Similarly, another finding demonstrated that in mMCP-4 knockout mice, the size of the infarcted area, ventricular remodeling, and apoptotic signaling were prominently reduced compared to those in the WT congeners [127]. Insulin-like growth factor-1 (IGF-1), a protective polypeptide, was degraded by mMCP4. Genetic deletion of Mcpt4 (the gene encoding mMCP4) reduced the infarction sizes and improved cardiac function via decreased degradation of IGF-1 [128]. These data firmly indicate the possible therapeutic roles of chymase blockage in post MI remodeling.

Sex differences in MC regulation between males and females have also been discovered. It has been verified that estrogen is capable of inhibiting pressure overload-induced cardiac remodeling. Similarly, after TAC surgery, ovariectomized (OVX) rats displayed more serious LV interstitial fibrosis and cardiac hypertrophy than sham-operated rats. Estrogen supplementation in TAC-OVX rats attenuated cardiac adverse remodeling by preventing $\mathrm{MC}$ chymase synthesis and release [129]. In accordance with this finding, administration of the mast cell stabilizer cromolyn sodium could mitigate changes in the wall thickness and LV mass and cardiac fibrosis in OVX female mice, providing evidence that $\mathrm{MC}$ antagonists are promising for the treatment of estrogen loss-induced LV remodeling (especially menopausal women) [130]. In summary, MCs are key cells modulating cardiac remodeling under a sexdependent mechanism. The clinical translation of research of sex differences in MCs may provide new insights into the treatment of patients of different genders.

\section{Endothelial cells}

Cardiac endothelial cells (ECs) are simple squamous epithelial cells present in the inner surface of the heart and blood vessels. ECs accounted for $64 \%$ of non-CMs in adult mice, outnumbering other cell types [60]. Genetic lineage tracing of cardiac resident cells by detecting stem cell antigen-1 (Sca-1) has uncovered that in mouse models of $\mathrm{MI}, \mathrm{Sca}-1^{+}$cells are a significant source of vascular endothelial cells, which accumulate heavily in heart tissue and quickly respond to ischemic stimuli [131]. In recent research, RNA sequencing technology was utilized to assess the transcriptome features of endothelial cells in cardiac remodeling. The data showed that 55 fetal genes were expressed in LAD-ligated hearts; the downregulated genes included Nbl1, Myoz2, Lbh, Gfra1, Gpx3 and Efemp, while the upregulated genes were Tnc, Anp32b, Thy1, Lpar4 and Car3 [132]. ECs participate in 
controlling CM contraction function as well as wound healing after pathological stress by secreting various biologically active substances, such as adhesion molecules (ICAM-1 and tenascin-C), profibrotic cytokines (endothelin-1, Ang II, TGF $\beta 1$, periostin, and connective tissue growth factor), proinflammatory mediators (IL-6 and IL-1 $\beta$ ), proangiogenetic factors (VEGF, PLGF, PDGF, bFGF, EGF, and HGF), cardioprotective mediators (follistatin-like 1, IGF-1, dickkopf-3, apelin, and LIF), some CXC chemokines, and other effectors [133-135].

\section{Pericytes}

Pericytes, which are also known as Rouget cells or parietal cells, are cells that surround ECs in capillaries and microvessels. Pericytes are identified by the expression of CD146, PDGFR- $\beta$, and alkaline phosphatase. The modulatory roles of pericytes are poorly understood. Previous studies have confirmed the potential reparative effects of pericytes. Combined delivery of pericytes and cardiac stem cells into the infarcted heart surprisingly improved cardiac contractility, as shown by echocardiographic, histological and molecular evaluations [136].
Moreover, in a swine model of AMI, transplantation of allogenic swine adventitial pericytes resulted in pro-angiogenic as well as anti-fibrotic outcomes [137].

\section{Conclusions}

Cardiac remodeling, which was once regarded as a simple outcome induced by an increased workload, has recently been shown by a growing number of studies to be a complex response to various cardiac pathophysiological stimuli, involving a range of infiltrating and activated cells (including CMs, a variety of inflammatory cells, and other non-CMs). Considering that the process of cardiac remodeling is roughly divided into the inflammatory and fibrotic phases, the significant roles of CFs and immune cells must be emphasized (Figure 3). It is of great value to understand the different cell phenotypes and their activation mechanisms in response to internal or external pathological stimuli in the heart. Although several therapies targeting different non-CMs have been reported recently (Table 1), a more adequate and comprehensive understanding of regulatory cell types is required for the development of potential clinical interventions.

Table 1. Recent advances in potential therapeutic approaches targeting non-CMs in cardiac remodeling

\begin{tabular}{|c|c|c|c|c|c|}
\hline Targeted cells & Potential therapy & Species & Disease model & Key observations & Mechanism \\
\hline \multirow[t]{7}{*}{$\begin{array}{l}\text { Cardiac } \\
\text { fibroblasts }\end{array}$} & NM922 [40] & mouse & $\begin{array}{l}\text { pressure overload-induced } \\
\text { cardiac hypertrophy and HF }\end{array}$ & $\begin{array}{l}\text { attenuated LV dilation and } \\
\text { hypertrophy, inhibited fibroblast } \\
\text { activation }\end{array}$ & $\begin{array}{l}\text { reducing the activation of FAK-Akt-P70S6K and } \\
\text { STAT3/E4-BP1 pathway }\end{array}$ \\
\hline & LCZ696 [41] & mouse & $\begin{array}{l}\text { left ventricle } \\
\text { pressure overload-induced } \\
\text { cardiac remodeling }\end{array}$ & $\begin{array}{l}\text { ameliorated pressure overload- } \\
\text { induced cardiac fibrosis }\end{array}$ & $\begin{array}{l}\text { restoration of PKG } \\
\text { (protein kinase G) signaling }\end{array}$ \\
\hline & $\begin{array}{l}\text { direct cardiac } \\
\text { reprogramming } \\
{[51]}\end{array}$ & human & - & $\begin{array}{l}\text { human adult fibroblasts were } \\
\text { reprogrammed into iCMs, along with } \\
\text { expression of cardiac markers, and } \\
\text { sarcomere-like structures }\end{array}$ & $\begin{array}{l}\text { inducement of cardiac transcription factors and } \\
\text { muscle-specific miRNAs }\end{array}$ \\
\hline & oleic acid [138] & mouse & $\begin{array}{l}\text { Ang II-induced cardiac } \\
\text { remodeling }\end{array}$ & $\begin{array}{l}\text { prevented Ang II-induced cardiac } \\
\text { fibrosis and improved heart function }\end{array}$ & $\begin{array}{l}\text { suppressing the expression of FGF23 (fibroblast } \\
\text { growth factor 23) }\end{array}$ \\
\hline & $\begin{array}{l}\text { DM-celecoxib } \\
{[139]}\end{array}$ & rat & $\begin{array}{l}\text { isoprenaline-induced cardiac } \\
\text { remodeling }\end{array}$ & $\begin{array}{l}\text { suppressed cardiac hypertrophy and } \\
\text { fibrosis }\end{array}$ & inhibiting Akt-mediated GSK-3 phosphorylation \\
\hline & simvastatin [140] & human & $\begin{array}{l}\text { TGF- } \beta 1 \text {-induced human } \\
\text { ventricular fibroblast } \\
\text { differentiation }\end{array}$ & $\begin{array}{l}\text { reduced hVF proliferation and } \\
\text { myofibroblast differentiation }\end{array}$ & $\begin{array}{l}\text { activation of protein-phosphatases PPM1A and } \\
\text { PP2A interacting with SMAD } 2 / 3\end{array}$ \\
\hline & Givinostat [141] & mouse & $\begin{array}{l}\text { acute myocardial infarction } \\
\text { generated by LAD ligation }\end{array}$ & $\begin{array}{l}\text { reduced cardiac fibrosis and } \\
\text { improved cardiac performance }\end{array}$ & $\begin{array}{l}\text { targeting endothelial-to-mesenchymal transition } \\
\text { (EndMT) }\end{array}$ \\
\hline \multirow[t]{9}{*}{$\begin{array}{l}\text { Cardiac } \\
\text { macrophages }\end{array}$} & $\begin{array}{l}\text { aminooxyacetic } \\
\text { acid [81] }\end{array}$ & mouse & $\begin{array}{l}\text { cardiac remodeling after LAD } \\
\text { ligation-induced MI }\end{array}$ & $\begin{array}{l}\text { attenuated post-MI cardiac } \\
\text { remodeling }\end{array}$ & $\begin{array}{l}\text { balancing M1/M2 macrophage phenotypes and } \\
\text { inhibiting NLRP3-Caspase1/IL-1 } \beta \text { pathway }\end{array}$ \\
\hline & $\begin{array}{l}\text { eicosapentaenoic } \\
\text { acid [80] }\end{array}$ & mouse & $\begin{array}{l}\text { cardiac remodeling after LAD } \\
\text { ligation-induced MI }\end{array}$ & $\begin{array}{l}\text { attenuated post-MI cardiac } \\
\text { remodeling }\end{array}$ & $\begin{array}{l}\text { inhibiting macrophage polarization toward } \\
\text { pro-inflammatory M1 phenotype }\end{array}$ \\
\hline & $\begin{array}{l}\text { hemin/HA-LP } \\
{[82]}\end{array}$ & mouse & post-MI cardiac remodeling & $\begin{array}{l}\text { improved infarct-related regional } \\
\text { function and promoted infarct healing }\end{array}$ & $\begin{array}{l}\text { switching macrophages toward M2 } \\
\text { anti-inflammatory phenotype }\end{array}$ \\
\hline & dapagliflozin [85] & rat & post-MI cardiac remodeling & attenuated cardiac fibrosis & $\begin{array}{l}\text { regulating macrophage phenotype through } \\
\text { RONS/STAT3-dependent pathway }\end{array}$ \\
\hline & $\begin{array}{l}\text { pioglitazone-NPs } \\
\text { [86] }\end{array}$ & mouse & post-MI cardiac remodeling & attenuated cardiac remodeling & $\begin{array}{l}\text { reducing macrophage recruitment and polarizing } \\
\text { macrophages towards the pro-healing M } 2 \\
\text { phenotype }\end{array}$ \\
\hline & $\begin{array}{l}\text { cardiac stem cell } \\
\text { therapy [87] }\end{array}$ & mouse & ischemia-reperfusion injury & enhanced cardiac function & $\begin{array}{l}\text { through an acute immune response, characterized } \\
\text { by a significant accumulation of } \mathrm{CCR} 2^{+} \text {and } \\
\text { CX3CR } 1^{+} \text {macrophages }\end{array}$ \\
\hline & $\begin{array}{l}\text { transplantation of } \\
\text { neonatal cardiac } \\
\text { macrophages [88] }\end{array}$ & mouse & post-MI cardiac remodeling & $\begin{array}{l}\text { improved MI-injured adult cardiac } \\
\text { repair }\end{array}$ & stimulating the proliferation of $\mathrm{CMs}$ \\
\hline & $\begin{array}{l}\text { Qishen Granule } \\
\text { [142] }\end{array}$ & rat & $\begin{array}{l}\text { cardiac remodeling after LAD } \\
\text { ligation-induced MI }\end{array}$ & attenuated myocardial fibrosis & $\begin{array}{l}\text { suppressing the recruitment of monocytes via } \\
\text { MCP1/CCR2 pathway, and balancing M1/M2 } \\
\text { macrophage phenotypes }\end{array}$ \\
\hline & miRNA-21 NPs & mouse & cardiac remodeling after LAD & reduced hypertrophy, fibrosis and cell & specifically targeting macrophages and eliciting \\
\hline
\end{tabular}




\begin{tabular}{|c|c|c|c|c|c|}
\hline Targeted cells & Potential therapy & Species & Disease model & Key observations & Mechanism \\
\hline & [143] & & ligation-induced MI & apoptosis & their phenotype switch from M1 to reparative M2 \\
\hline Neutrophils & memantine [144] & rat & isoproterenol-induced HF & $\begin{array}{l}\text { reduced cardiac remodeling and } \\
\text { improved cardiac performance }\end{array}$ & $\begin{array}{l}\text { reducing lipid peroxidation and neutrophil } \\
\text { infiltration }\end{array}$ \\
\hline \multirow[t]{3}{*}{ Lymphocytes } & $\begin{array}{l}\text { tolerogenic } \\
\text { dendritic cells } \\
{[118]}\end{array}$ & mouse & $\begin{array}{l}\text { cardiac remodeling after LAD } \\
\text { ligation-induced MI }\end{array}$ & $\begin{array}{l}\text { improved cardiac remodeling, } \\
\text { preserved left ventricular systolic } \\
\text { function, and improved survival }\end{array}$ & $\begin{array}{l}\text { inducing a systemic activation of MI-specific Treg } \\
\text { cells }\end{array}$ \\
\hline & $\begin{array}{l}\text { CD8+ OT-I T cells } \\
{[119]}\end{array}$ & mouse & $\begin{array}{l}\text { Ang II/PE-induced cardiac } \\
\text { fibrosis }\end{array}$ & $\begin{array}{l}\text { attenuated myocardial fibrosis and } \\
\text { hypertrophy }\end{array}$ & directly modifying $\mathrm{T}$ cells \\
\hline & rituximab [145] & mouse & $\begin{array}{l}\text { pressure overload-induced } \\
\text { cardia remodeling }\end{array}$ & $\begin{array}{l}\text { suppressed myocyte hypertrophy, } \\
\text { fibrosis and oxidative stress, and } \\
\text { improved heart function }\end{array}$ & $\begin{array}{l}\text { inhibiting pro-inflammatory cytokines and Th2 } \\
\text { cytokine-mediated IgG production from B cells }\end{array}$ \\
\hline \multirow[t]{4}{*}{ Endothelial cells } & serelaxin [146] & mouse & $\begin{array}{l}\text { cardiac fibrosis induced by } \\
\text { ascending aortic constriction } \\
\text { (AAC) and Ang II infusion }\end{array}$ & $\begin{array}{l}\text { attenuated myocardial fibrosis in both } \\
\text { models }\end{array}$ & $\begin{array}{l}\text { preventing EndMT through the endothelial } \\
\text { Relaxin family peptide receptor } 1\end{array}$ \\
\hline & $\begin{array}{l}\text { VEGF } \\
\text { nanoparticles } \\
{[147]}\end{array}$ & mouse & post-MI cardiac remodeling & $\begin{array}{l}\text { increased vascular density in the } \\
\text { peri-infarct region, and improved the } \\
\text { LV contractile function } 4 \text { weeks after } \\
\text { treatment }\end{array}$ & $\begin{array}{l}\text { promoting neovascularization in the infarcted } \\
\text { heart }\end{array}$ \\
\hline & $\begin{array}{l}\text { VEGF-B gene } \\
\text { therapy [148] }\end{array}$ & mouse & $\begin{array}{l}\text { doxorubicin-induced } \\
\text { cardiomyopathy }\end{array}$ & $\begin{array}{l}\text { reduced whole-body wasting, and } \\
\text { improved pathological remodeling, }\end{array}$ & $\begin{array}{l}\text { protecting endothelial cells from apoptosis and } \\
\text { restoring their normal function }\end{array}$ \\
\hline & $\begin{array}{l}\text { VEGFA/S1P-deliv } \\
\text { eried bone } \\
\text { marrow cells [149] }\end{array}$ & mouse & post-MI cardiac remodeling & $\begin{array}{l}\text { increased endothelial cells, prevented } \\
\text { cardiac fibrogenesis and adverse } \\
\text { cardiac remodeling }\end{array}$ & $\begin{array}{l}\text { improving micro-vascularization and oxygen } \\
\text { diffusion }\end{array}$ \\
\hline
\end{tabular}

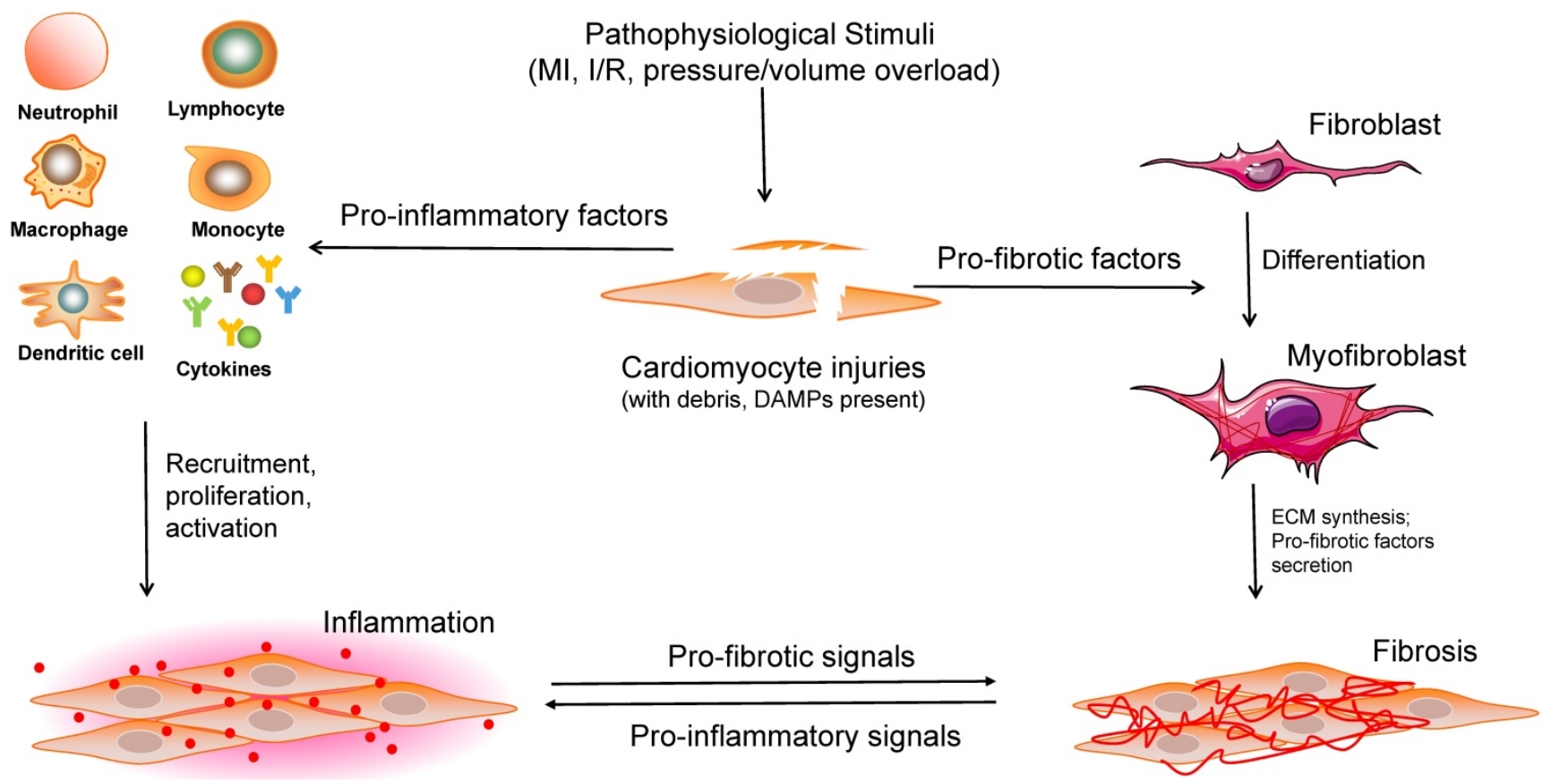

Figure 3. Overview of the interactions between cardiomyocytes and noncardiomyocytes in the process of cardiac remodeling. When stimulated by various pathophysiological insults, large numbers of cell debris, regulatory factors, and DAMPs are expanded in the injured heart tissue. Subsequently, a range of immune cells are recruited, proliferated and activated to induce inflammation. Moreover, pro-fibrotic factors contribute to fibroblast-to-myofibroblast transition, ECM synthesis, pro-fibrotic cytokines secretion, and cardiac fibrosis. DAMPs: damage-associated molecular pattern molecules, ECM: extracellular matrix.

With the wide use of selective depletion and conditional gene knockout methods, the effects of certain cells in cardiac remodeling have been gradually revealed. However, until now, most research has focused on MI murine models and ignored the cellular phenotypes and potential signaling pathways involved in other CVDs. In addition, single studies often focus on the effects of one specific cell type in a certain phase, and studies that simultaneously explore multiple cell types and their interactions that contribute to cardiac remodeling are very rare. Importantly, although many animal studies have revealed detrimental or protective effects of non-CMs on tissue remodeling, preclinical or clinical investigations are still lacking, and wide gaps exist between the bench and the bedside. In view of the heterogeneity and complexity of non-CMs in the regulation of cardiac remodeling, deeper exploration is urgently needed to dissect the cell biology and to find new therapeutic strategies; furthermore, an improved understanding is required to identify the patients who may benefit from the new findings. 


\section{Abbreviations}

Akt: protein kinase B; bFGF: basic fibroblast growth factor; $\mathrm{BMC}$ : bone marrow-derived cell; $\mathrm{CCL}$ : chemokine $\mathrm{C}-\mathrm{C}$ motif ligand; $\mathrm{CCR}$ : $\mathrm{C}-\mathrm{C}$ chemokine receptor; CF: cardiac fibroblast; CM: cardiomyocyte; COX: cyclooxygenase; CVD: cardiovascular disease; CXCL: C-X-C motif chemokine ligand; CX3CR1: CX3C chemokine receptor 1; DAMP: dangerassociated molecular pattern; DDR2: discoidin domain receptor 2; EC: endothelial cell; ECM: extracellular matrix; eGFP: enhanced green fluorescent protein; EMT: epithelial-to-mesenchymal transition; EndMT: endothelial-mesenchymal transition; EPAC1: exchange protein activated by cyclic AMP 1; EPDC: epicardium-derived progenitor cell; ERK: extracellular regulated protein kinase; FAP: fibroblast activation protein; Foxp3: forkhead box protein 3; HF: heart failure; ICAM: intercellular cell adhesion molecule; IGF-1: insulin-like growth factor-1; IL: interleukin; LV: left ventricle; Ly-6C: lymphocyte antigen 6C; LYVE1: lymphatic vessel endothelial hyaluronan receptor-1; MAPK: mitogenactivated protein kinase; MC: mast cell; MCP: monocyte chemoattractant protein; MHC-II: major histocompatibility complex class II; MI: myocardial infarction; MK5: MAP kinase-activated protein kinase 5; mMCP4: mouse mast cell protease-4; MMP: matrix metalloproteinase; MRTF: myocardin-related transcription factors; MSC: mesenchymal stem cell; mTOR: mammalian target of rapamycin; MYD88: myeloid differentiation primary response 88; NGAL: neutrophil gelatinase-associated lipocalin; Non-CM: noncardiomyocyte; PAB: pulmonary artery banding; PC1: polycystin-1; PDGF: platelet derived growth factor; PDGFR- $\beta$ : platelet derived growth factor receptor beta; PKG: protein kinase G; PPARy: peroxisome proliferator-activated receptor $\gamma$; ROS: reactive oxygen species; Sca-1: stem cell antigen-1; SRF: serum response factor; STAT3: signal transducer and activator of transcription 3; TAC: transverse aortic constriction; TGF- $\beta$ : transforming growth factor-beta; TIMD4: T-cell immunoglobulin and mucin domain containing protein 4; TNFR1: tumor necrosis factor receptor 1; Tregs: regulatory $\mathrm{T}$ cells; TRM: tissue resident macrophage; VEGF: vascular endothelial growth factor; YFP: yellow fluorescent protein; YS: yolk sac.

\section{Acknowledgements}

This work was supported by grants from the National Natural Science Foundation of China (81900219, 81530012, 81800216), National Key R\&D Program of China (2018YFC1311300), the Fundamental Research Funds for the Central
Universities (2042019kf0062, 2042018kf1032), Development Center for Medical Science and Technology National Health and Family Planning Commission of the People's Republic of China (2016ZX-008-01).

\section{Competing Interests}

The authors have declared that no competing interest exists.

\section{References}

1. Garza MA, Wason EA, Zhang JQ. Cardiac remodeling and physical training post myocardial infarction. World Journal of Cardiology. 2015; 7: 52-64.

2. Tadic M, Cuspidi C. Childhood obesity and cardiac remodeling: from cardiac structure to myocardial mechanics. J Cardiovasc Med. 2015; 16: 538-546.

3. Weiner RB, Baggish AL. Exercise-Induced Cardiac Remodeling. Prog in Cardiovasc Dis. 2012; 54: 380-386.

4. Aimo A, Gaggin HK, Barison A, Emdin M, Jr. Januzzi JL. Imaging, Biomarker, and Clinical Predictors of Cardiac Remodeling in Heart Failure With Reduced Ejection Fraction. JACC-Heart Failure. 2019; 7: 782-794.

5. Alpert MA, Karthikeyan K, Abdullah O, Ghadban R. Obesity and Cardiac Remodeling in Adults: Mechanisms and Clinical Implications. Prog in Cardiovasc Dis. 2018; 61: 114-123.

6. Cha YM, Dzeja PP, Shen WK, Jahangir A, Hart CY, Terzic A et al. Failing atrial myocardium: energetic deficits accompany structural remodeling and electrical instability. Am J Physiol Heart Circ Physiol. 2003; 284: H1313-H1320.

7. Kim GH, Uriel N, Burkhoff D. Reverse remodelling and myocardial recovery in heart failure. Nat Rev Cardiol. 2018; 15: 83-96.

8. Wolfien M, Galow AM, Muller P, Bartsch M, Brunner RM, Goldammer T et al. Single-Nucleus Sequencing of an Entire Mammalian Heart: Cell Type Composition and Velocity. Cells. 2020; 9: 318.

9. Wang L, Yu P, Zhou B, Song J, Li Z, Zhang M et al. Single-cell reconstruction of the adult human heart during heart failure and recovery reveals the cellular landscape underlying cardiac function. Nat Cell Biol. 2020; 22: 108-119.

10. Feng J, Li Y, Nie Y. Non-Cardiomyocytes in Heart Regeneration. Curr Drug Targets. 2018; 19: 1077-1086.

11. Frieler RA, Mortensen RM. Immune cell and other noncardiomyocyte regulation of cardiac hypertrophy and remodeling. Circulation. 2015; 131: 1019-1030

12. Shinde AV, Frangogiannis NG. Fibroblasts in myocardial infarction: A role in inflammation and repair. J Mol Cell Cardiol. 2014; 70: 74-82.

13. Kanisicak O, Khalil H, Ivey MJ, Karch J, Maliken BD, Correll RN et al. Genetic lineage tracing defines myofibroblast origin and function in the injured heart. Nat Commun. 2016; 7: 12260.

14. Kaur H, Takefuji M, Ngai CY, Carvalho J, Bayer J, Wietelmann A et al. Targeted Ablation of Periostin-Expressing Activated Fibroblasts Prevents Adverse Cardiac Remodeling in Mice. Circ Res. 2016; 118: 1906-1917.

15. Acharya A, Baek ST, Banfi S, Eskiocak B, Tallquist MD. Efficient inducible Cre-mediated recombination in Tcf21 cell lineages in the heart and kidney. Genesis. 2011; 49: 870-877.

16. von Gise A, Zhou B, Honor LB, Ma Q, Petryk A, Pu WT. WT1 regulates epicardial epithelial to mesenchymal transition through $\beta$-catenin and retinoic acid signaling pathways. Developmental Biology. 2011; 356: 421-431.

17. Small EM. The actin-MRTF-SRF gene regulatory axis and myofibroblast differentiation. J Cardiovasc Transl Res. 2012; 5: 794-804.

18. Quijada P, Misra A, Velasquez LS, Burke RM, Lighthouse JK, Mickelsen DM et al. Pre-existing fibroblasts of epicardial origin are the primary source of pathological fibrosis in cardiac ischemia and aging. J Mol Cell Cardiol. 2019; 129: 92-104.

19. Ali SR, Ranjbarvaziri S, Talkhabi M, Zhao P, Subat A, Hojjat A et al. Developmental heterogeneity of cardiac fibroblasts does not predict pathological proliferation and activation. Circ Res. 2014; 115: 625-635.

20. Moore-Morris T, Guimaraes-Camboa N, Banerjee I, Zambon AC, Kisseleva T, Velayoudon A et al. Resident fibroblast lineages mediate pressure overload-induced cardiac fibrosis. J Clin Invest. 2014; 124: 2921-2934.

21. Zeisberg EM, Tarnavski O, Zeisberg M, Dorfman AL, McMullen JR, Gustafsson E et al. Endothelial-to-mesenchymal transition contributes to cardiac fibrosis. Nat Med. 2007; 13: 952-961.

22. Rafael K, K SR, P DD, Flavia M, Susanne F, A BP et al. Perivascular Gli1+ progenitors are key contributors to injury-induced organ fibrosis. Cell stem cell. 2015; 16: 51-66.

23. Moellmann H, Nef HM, Kostin S, von Kalle C, Pilz I, Weber M et al. Bone marrow-derived cells contribute to infarct remodelling. Cardiovasc Res. 2006; 71: 661-671.

24. Fujita J, Mori M, Kawada H, Ieda Y, Tsuma M, Matsuzaki $\mathrm{Y}$ et al. Administration of granulocyte colony-stimulating factor after myocardial infarction enhances the recruitment of hematopoietic stem cell-derived myofibroblasts and contributes to cardiac repair. Stem Cells. 2007; 25: 2750-2759. 
25. She G, Ren $Y$, Wang $Y$, Hou M, Wang H, Gou W et al. K(Ca)3.1 Channels Promote Cardiac Fibrosis Through Mediating Inflammation and Differentiation of Monocytes Into Myofibroblasts in Angiotensin II-Treated Rats. J Am Heart Assoc. 2019; 8: e010418.

26. Haider N, Bosca L, Zandbergen HR, Kovacic JC, Narula N, Gonzalez-Ramos S et al. Transition of Macrophages to Fibroblast-Like Cells in Healing Myocardial Infarction. J Am Coll Cardiol. 2019; 74: 3124-3135.

27. Fu X, Khalil H, Kanisicak O, Boyer JG, Vagnozzi RJ, Maliken BD et al. Specialized fibroblast differentiated states underlie scar formation in the infarcted mouse heart. J Clin Invest. 2018; 128: 2127-2143.

28. Harikrishnan V, Titus AS, Cowling RT, Kailasam S. Collagen receptor cross-talk determines a-smooth muscle actin-dependent collagen gene expression in angiotensin II-stimulated cardiac fibroblasts. J Biol Chem. 2019; 294: 19723-19739.

29. Villalobos E, Criollo A, Schiattarella GG, Altamirano F, French KM, May HI et al. Fibroblast Primary Cilia Are Required for Cardiac Fibrosis. Circulation. 2019; 139: 2342-2357.

30. Blythe NM, Muraki K, Ludlow MJ, Stylianidis V, Gilbert HTJ, Evans EL et al. Mechanically activated Piezo1 channels of cardiac fibroblasts stimulate p38 mitogen-activated protein kinase activity and interleukin-6 secretion. J Biol Chem. 2019; 294: 17395-17408.

31. Yu J, Seldin MM, Fu K, Li S, Lam L, Wang P et al. Topological Arrangement of Cardiac Fibroblasts Regulates Cellular Plasticity. Circ Res. 2018; 123: 73-85.

32. Nawaito SA, Sahadevan P, Sahmi F, Gaestel M, Calderone A, Allen BG. Transcript levels for extracellular matrix proteins are altered in MK5-deficient cardiac ventricular fibroblasts. J Mol Cell Cardiol. 2019; 132: 164-177.

33. Feng J, Armillei MK, Yu AS, Liang BT, Runnels LW, Yue L. Ca(2+) Signaling in Cardiac Fibroblasts and Fibrosis-Associated Heart Diseases. J Cardiovasc Dev Dis. 2019; 6: 34.

34. Yue Z, Zhang Y, Xie J, Jiang J, Yue L. Transient receptor potential (TRP) channels and cardiac fibrosis. Curr Top Med Chem. 2013; 13: 270-282.

35. Hof T, Chaigne S, Récalde A, Sallé L, Brette F, Guinamard R. Transient receptor potential channels in cardiac health and disease. Nat Rev Cardiol. 2019; 16: 344-360.

36. Varasteh Z, Mohanta S, Robu S, Braeuer M, Li Y, Omidvari N et al. Molecular Imaging of Fibroblast Activity After Myocardial Infarction Using a Ga-68-Labeled Fibroblast Activation Protein Inhibitor, FAPI-04. J Nucl Med. 2019; 60: 1743-1749.

37. Awada HK, Johnson NR, Wang Y. Sequential delivery of angiogenic growth factors improves revascularization and heart function after myocardial infarction. J Control Release. 2015; 207: 7-17.

38. Formiga FR, Tamayo E, Simon-Yarza T, Pelacho B, Prosper F, Blanco-Prieto MJ. Angiogenic therapy for cardiac repair based on protein delivery systems. Heart Fail Rev. 2012; 17: 449-473.

39. Fan Z, Xu Z, Niu H, Sui Y, Li H, Ma J et al. Spatiotemporal delivery of basic fibroblast growth factor to directly and simultaneously attenuate cardiac fibrosis and promote cardiac tissue vascularization following myocardial infarction. J Control Release. 2019; 311: 233-244.

40. Bradley JM, Spaletra P, Li Z, Sharp TEI, Goodchild TT, Corral LG et al. A novel fibroblast activation inhibitor attenuates left ventricular remodeling and preserves cardiac function in heart failure. Am J Physiol Heart Circ Physiol. 2018; 315: H563-H570.

41. Burke RM, Lighthouse JK, Mickelsen DM, Small EM. Sacubitril/Valsartan Decreases Cardiac Fibrosis in Left Ventricle Pressure Overload by Restoring PKG Signaling in Cardiac Fibroblasts. Circ-Heart Fail. 2019; 12: e005565.

42. Surinkaew S, Aflaki M, Takawale A, Chen Y, Qi X, Gillis M et al. Exchange protein activated by cyclic-adenosine monophosphate (Epac) regulates atrial fibroblast function and controls cardiac remodelling. Cardiovasc Res. 2019; 115: 94-106.

43. Li H, Bao M, Nie Y. Extracellular matrix-based biomaterials for cardiac regeneration and repair. Heart Fail Rev. 2020. [Epub ahead of print]

44. Bektik E, Fu JD. Ameliorating the Fibrotic Remodeling of the Heart through Direct Cardiac Reprogramming. Cells. 2019; 8: 679

45. Tani H, Sadahiro T, Ieda M. Direct Cardiac Reprogramming: A Novel Approach for Heart Regeneration. Int J Mol Sci. 2018; 19: 2629.

46. Ieda M, Fu JD, Delgado-Olguin P, Vedantham V, Hayashi Y, Bruneau BG et al. Direct reprogramming of fibroblasts into functional cardiomyocytes by defined factors. Cell. 2010; 142: 375-386.

47. Song K, Nam YJ, Luo X, Qi X, Tan W, Huang GN et al. Heart repair by reprogramming non-myocytes with cardiac transcription factors. Nature. 2012; 485: 599-604

48. Hirai $\mathrm{H}$, Katoku-Kikyo N, Keirstead SA, Kikyo N. Accelerated direct reprogramming of fibroblasts into cardiomyocyte-like cells with the MyoD transactivation domain. Cardiovasc Res. 2013; 100: 105-113.

49. Muraoka N, Yamakawa H, Miyamoto K, Sadahiro T, Umei T, Isomi M et al. MiR-133 promotes cardiac reprogramming by directly repressing Snai1 and silencing fibroblast signatures. EMBO J. 2014; 33: 1565-1581.

50. Protze S, Khattak S, Poulet C, Lindemann D, Tanaka EM, Ravens U. A new approach to transcription factor screening for reprogramming of fibroblasts to cardiomyocyte-like cells. J Mol Cell Cardiol. 2012; 53: 323-332.

51. Nam YJ, Song K, Luo X, Daniel E, Lambeth K, West K et al. Reprogramming of human fibroblasts toward a cardiac fate. Proc Natl Acad Sci U S A. 2013; 110 : 5588-5593.
52. Mohamed TM, Stone NR, Berry EC, Radzinsky E, Huang Y, Pratt K et al. Chemical Enhancement of In Vitro and In Vivo Direct Cardiac Reprogramming. Circulation. 2017; 135: 978-995.

53. Han C, Nie Y, Lian H, Liu R, He F, Huang H et al. Acute inflammation stimulates a regenerative response in the neonatal mouse heart. Cell Res. 2015; 25: 1137-1151.

54. Zhang Y, Bauersachs J, Langer HF. Immune mechanisms in heart failure. Eur J Heart Fail. 2017; 19: 1379-1389.

55. Prabhu SD, Frangogiannis NG. The Biological Basis for Cardiac Repair After Myocardial Infarction: From Inflammation to Fibrosis. Circ Res. 2016; 119: 91-112.

56. Hu YF, Chen YJ, Lin YJ, Chen SA. Inflammation and the pathogenesis of atrial fibrillation. Nat Rev Cardiol. 2015; 12: 230-243.

57. Andreadou I, Cabrera-Fuentes HA, Devaux Y, Frangogiannis NG, Frantz S, Guzik $\mathrm{T}$ et al. Immune cells as targets for cardioprotection: new players and novel therapeutic opportunities. Cardiovasc Res. 2019; 115: 1117-1130.

58. Zhang Y, Huang Z, Li H. Insights into innate immune signalling in controlling cardiac remodelling. Cardiovasc Res. 2017; 113: 1538-1550.

59. Latet SC, Hoymans VY, Van Herck PL, Vrints CJ. The cellular immune system in the post-myocardial infarction repair process. Int J Cardiol. 2015; 179: 240-247

60. Pinto AR, Ilinykh A, Ivey MJ, Kuwabara JT, D'Antoni ML, Debuque R et al. Revisiting Cardiac Cellular Composition. Circ Res. 2016; 118: 400-409.

61. Weinberger T, Schulz C. Myocardial infarction: a critical role of macrophages in cardiac remodeling. Front Physiol. 2015; 6: 107

62. Kratofil RM, Kubes P, Deniset JF. Monocyte Conversion During Inflammation and Injury. Arterioscler Thromb Vasc Biol. 2017; 37: 35-42.

63. Peet C, Ivetic A, Bromage DI, Shah AM. Cardiac monocytes and macrophages after myocardial infarction. Cardiovasc Res. 2019; 0: 1-12.

64. Hulsmans M, Sam F, Nahrendorf M. Monocyte and macrophage contributions to cardiac remodeling. J Mol Cell Cardiol. 2016; 93: 149-155.

65. Mingjie Y, Lei S, Lai W, Ada Y, Haley R, Fuqiang L et al. Deficiency of GATA3-Positive Macrophages Improves Cardiac Function Following Myocardial Infarction or Pressure Overload Hypertrophy. J Am Coll Cardiol. 2018; 72: 885-904.

66. Davies LC, Taylor PR. Tissue-resident macrophages: then and now. Immunology. 2015; 144: 541-548.

67. Ginhoux F, Guilliams M. Tissue-Resident Macrophage Ontogeny and Homeostasis. Immunity. 2016; 44: 439-449.

68. Hoeffel G, Ginhoux F. Fetal monocytes and the origins of tissue-resident macrophages. Cell Immunol. 2018; 330: 5-15.

69. Bajpai G, Bredemeyer A, Li W, Zaitsev K, Koenig AL, Lokshina I et al. Tissue Resident CCR2-and CCR2+Cardiac Macrophages Differentially Orchestrate Monocyte Recruitment and Fate Specification Following Myocardial Injury. Circ Res. 2019; 124: 263-278.

70. Bajpai G, Schneider C, Wong N, Bredemeyer A, Hulsmans M, Nahrendorf M et al. The human heart contains distinct macrophage subsets with divergent origins and functions. Nat Med. 2018; 24: 1234-1245.

71. Dick SA, Macklin JA, Nejat S, Momen A, Clemente-Casares X, Althagafi MG et al. Self-renewing resident cardiac macrophages limit adverse remodeling following myocardial infarction. Nat Immunol. 2019; 20: 29-39.

72. Heo GS, Kopecky B, Sultan D, Ou M, Feng G, Bajpai G et al. Molecular Imaging Visualizes Recruitment of Inflammatory Monocytes and Macrophages to the Injured Heart. Circ Res. 2019; 124: 881-890.

73. Nicolas-Avila JA, Hidalgo A, Ballesteros I. Specialized functions of resident macrophages in brain and heart. J Leukoc Biol. 2018; 104: 743-756.

74. Deniset JF, Belke D, Lee W, Jorch SK, Deppermann C, Hassanabad AF et al. Gata6(+) Pericardial Cavity Macrophages Relocate to the Injured Heart and Prevent Cardiac Fibrosis. Immunity. 2019; 51: 131-140.

75. Ma Y, Mouton AJ, Lindsey ML. Cardiac macrophage biology in the steady-state heart, the aging heart, and following myocardial infarction. Transl Res. 2018; 191: 15-28.

76. Gombozhapova A, Rogovskaya Y, Shurupov V, Rebenkova M, Kzhyshkowska J, Popov SV et al. Macrophage activation and polarization in post-infarction cardiac remodeling. J Biomed Sci. 2017; 24: 13.

77. Jung M, Ma Y, Iyer RP, DeLeon-Pennell KY, Yabluchanskiy A, Garrett MR et al. IL-10 improves cardiac remodeling after myocardial infarction by stimulating M2 macrophage polarization and fibroblast activation. Basic Res Cardiol. 2017: 112:3.

78. Mouton AJ, DeLeon-Pennell KY, Gonzalez OJR, Flynn ER, Freeman TC, Saucerman JJ et al. Mapping macrophage polarization over the myocardial infarction time continuum. Basic Res Cardiol. 2018; 113: 26.

79. Ryabov V, Gombozhapova A, Rogovskaya Y, Kzhyshkowska J, Rebenkova M, Karpov R. Cardiac CD68+and stabilin-1+macrophages in wound healing following myocardial infarction: From experiment to clinic. Immunobiology. 2018; 223: 413-421.

80. Takamura M, Kurokawa K, Ootsuji H, Inoue O, Okada H, Nomura A et al. Long-Term Administration of Eicosapentaenoic Acid Improves Post-Myocardial Infarction Cardiac Remodeling in Mice by Regulating Macrophage Polarization. J Am Heart Assoc. 2017; 6: e004560.

81. Zhao P, Zhou W, Zhang Y, Li J, Zhao Y, Pan L et al. Aminooxyacetic acid attenuates post-infarct cardiac dysfunction by balancing macrophage polarization through modulating macrophage metabolism in mice. J Cell Mol Med. 2020; 24: 2593-2609. 
82. Ben-Mordechai T, Kain D, Holbova R, Landa N, Levin L, Elron-Gross I et al. Targeting and modulating infarct macrophages with hemin formulated in designed lipid-based particles improves cardiac remodeling and function. J Control Release. 2017; 257: 21-31.

83. Mongue-Din H, Patel AS, Looi YH, Grieve DJ, Anilkumar N, Sirker A et al. NADPH Oxidase-4 Driven Cardiac Macrophage Polarization Protects Against Myocardial Infarction-Induced Remodeling. JACC. Basic to translational science 2017; 2: 688-698.

84. Wang N, Liu C, Wang X, He T, Li L, Liang X et al. Hyaluronic Acid Oligosaccharides Improve Myocardial Function Reconstruction and Angiogenesis against Myocardial Infarction by Regulation of Macrophages. Theranostics. 2019; 9: 1980-1992.

85. Lee T, Chang N, Lin S. Dapagliflozin, a selective SGLT2 Inhibitor, attenuated cardiac fibrosis by regulating the macrophage polarization via STAT3 signaling in infarcted rat hearts. Free Radical Bio Med. 2017; 104: 298-310.

86. Tokutome M, Matoba T, Nakano Y, Okahara A, Fujiwara M, Koga J et al. Peroxisome proliferator-activated receptor-gamma targeting nanomedicine promotes cardiac healing after acute myocardial infarction by skewing monocyte/macrophage polarization in preclinical animal models. Crdiovasc Res. 2019; 115: 419-431.

87. Vagnozzi RJ, Maillet M, Sargent MA, Khalil H, Johansen A, Schwanekamp JA et al. An acute immune response underlies the benefit of cardiac stem cell therapy. Nature. 2020; 577: 405-409.

88. Li Y, Li H, Pei J, Hu S, Nie Y. Transplantation of murine neonatal cardiac macrophage improves adult cardiac repair. Cell Mol Immunol. 2020. [Epub ahead of print].

89. Puhl S, Steffens S. Neutrophils in Post-myocardial Infarction Inflammation: Damage vs. Resolution? Front Cardiovasc Med. 2019; 6: 25.

90. Tourki B, Halade G. Leukocyte diversity in resolving and nonresolving mechanisms of cardiac remodeling. FASEB J. 2017; 31: 4226-4239.

91. Kolodziej AR, Abo-Aly M, Elsawalhy E, Campbell C, Ziada KM, Abdel-Latif A. Prognostic Role of Elevated Myeloperoxidase in Patients with Acute Coronary Syndrome: A Systemic Review and Meta-Analysis. Mediators Inflamm. 2019; 2019: 2872607.

92. Ma Y, Yabluchanskiy A, Iyer RP, Cannon PL, Flynn ER, Jung M et al. Temporal neutrophil polarization following myocardial infarction. Cardiovasc Res. 2016; 110: 51-61.

93. Daseke MJ, Valerio FM, Kalusche WJ, Ma Y, DeLeon-Pennell KY, Lindsey ML. Neutrophil proteome shifts over the myocardial infarction time continuum. Basic Res Cardiol. 2019; 114: 37.

94. Yndestad A, Landro L, Ueland T, Dahl CP, Flo TH, Vinge LE et al. Increased systemic and myocardial expression of neutrophil gelatinase-associated lipocalin in clinical and experimental heart failure. Eur Heart J. 2009; 30: 1229-1236.

95. Hemdahl AL, Gabrielsen A, Zhu CY, Eriksson P, Hedin U, Kastrup J et al. Expression of neutrophil gelatinase-associated lipocalin in atherosclerosis and myocardial infarction. Arterioscl Throm Vas. 2006; 26: 136-142.

96. Martinez-Martinez E, Buonafine M, Boukhalfa I, Ibarrola J, Fernandez-Celis A, Kolkhof P et al. Aldosterone Target NGAL (Neutrophil Gelatinase-Associated Lipocalin) Is Involved in Cardiac Remodeling After Myocardial Infarction Through NF kappa B Pathway. Hypertension. 2017; 70: 1148-1156.

97. Buonafine M, Martinez-Martinez E, Amador C, Gravez B, Ibarrola J, Fernandez-Celis A et al. Neutrophil Gelatinase-Associated Lipocalin from immune cells is mandatory for aldosterone-induced cardiac remodeling and inflammation. J Mol Cell Cardiol. 2018; 115: 32-38.

98. Shalenkova MA, Mikhailova ZD, Klimkin PF. NGAL as a Marker for Some Extrarenal Complications in Acute Coronary Syndrome. Kardiologiya. 2018; 583: 19-26.

99. Horckmans M, Ring L, Duchene J, Santovito D, Schloss MJ, Drechsler M et al. Neutrophils orchestrate post-myocardial infarction healing by polarizing macrophages towards a reparative phenotype. Eur Heart J. 2017; 38: 187-197.

100. Kessler EL, Rivaud MR, Vos MA, van Veen T. Sex-specific influence on cardiac structural remodeling and therapy in cardiovascular disease. Biol Sex Differ. 2019; $10: 7$.

101. DeLeon-Pennell KY, Mouton AJ, Ero OK, Ma Y, Iyer RP, Flynn ER et al. LXR/RXR signaling and neutrophil phenotype following myocardial infarction classify sex differences in remodeling. Basic Res Cardiol. 2018; 113: 40.

102. Liu Y, Lu H, Zhang C, Hu J, Xu D. Recent advances in understanding the roles of $\mathrm{T}$ cells in pressure overload-induced cardiac hypertrophy and remodeling. J Mol Cell Cardiol. 2019; 129: 293-302.

103. Ramos G, Hofmann U, Frantz S. Myocardial fibrosis seen through the lenses of T-cell biology. J Mol Cell Cardiol. 2016; 92: 41-45.

104. Cordero-Reyes AM, Youker KA, Trevino AR, Celis R, Hamilton DJ, Flores-Arredondo $\mathrm{JH}$ et al. Full Expression of Cardiomyopathy Is Partly Dependent on B-Cells: A Pathway That Involves Cytokine Activation, Immunoglobulin Deposition, and Activation of Apoptosis. J Am Heart Assoc. 2016; 5: e002484

105. Nunes-Silva V, Frantz S, Ramos GC. Lymphocytes at the Heart of Wound Healing. Adv Exp Med Biol. 2017; 1003: 225-250.

106. Blanton RM, Carrillo-Salinas FJ, Alcaide P. T-cell recruitment to the heart: friendly guests or unwelcome visitors? Am J Physiol Heart Circ Physiol. 2019; 317: H124-H140.

107. Wang Y, Dembowsky K, Chevalier E, Stueve P, Korf-Klingebiel M, Lochner M et al. C-X-C Motif Chemokine Receptor 4 Blockade Promotes Tissue Repair
After Myocardial Infarction by Enhancing Regulatory T Cell Mobilization and Immune-Regulatory Function. Circulation. 2019; 139: 1798-1812.

108. Ngwenyama N, Salvador AM, Velazquez F, Nevers T, Levy A, Aronovitz M et al. CXCR3 regulates CD4(+) T cell cardiotropism in pressure overload-induced cardiac dysfunction. JCI Insight. 2019; 4: 125527.

109. Bansal SS, Ismahil MA, Goel M, Patel B, Hamid T, Rokosh G et al. Activated T Lymphocytes are Essential Drivers of Pathological Remodeling in Ischemic Heart Failure. Circ-Heart Fail. 2017; 10: e003688.

110. Tang T, Zhu Y, Dong N, Zhang S, Cai J, Zhang L et al. Pathologic T-cell response in ischaemic failing hearts elucidated by $\mathrm{T}$-cell receptor sequencing and phenotypic characterization. Eur Heart J. 2019; 40: 3924-3933.

111. Tang T, Yuan J, Zhu Z, Zhang W, Xiao H, Xia N et al. Regulatory T cells ameliorate cardiac remodeling after myocardial infarction. Basic Res Cardiol. 2012; 107: 232.

112. Weirather J, Hofmann UDW, Beyersdorf N, Ramos GC, Vogel B, Frey A et al. Foxp $(3+)$ CD4+ T Cells Improve Healing After Myocardial Infarction by Modulating Monocyte/Macrophage Differentiation. Circ Res. 2014; 115: 55-67.

113. Saxena A, Dobaczewski M, Rai V, Haque Z, Chen W, Li N et al. Regulatory T cells are recruited in the infarcted mouse myocardium and may modulate fibroblast phenotype and function. J Am J Physiol Heart Circ Physiol. 2014; 307: H1233-H1242.

114. Sharir R, Semo J, Shimoni S, Ben-Mordechai T, Landa-Rouben N, Maysel-Auslender $\mathrm{S}$ et al. Experimental Myocardial Infarction Induces Altered Regulatory T Cell Hemostasis, and Adoptive Transfer Attenuates Subsequent Remodeling. Plos One. 2014; 9: e113653.

115. Bansal SS, Ismahil MA, Goel M, Zhou G, Rokosh G, Hamid T et al. Dysfunctional and Proinflammatory Regulatory T-Lymphocytes Are Essential or Adverse Cardiac Remodeling in Ischemic Cardiomyopathy. Circulation. 2019; 139: 206-221.

116. Cordero-Reyes AM, Youker KA, Trevino AR, Celis R, Hamilton DJ, Flores-Arredondo $\mathrm{JH}$ et al. Full Expression of Cardiomyopathy Is Partly Dependent on B-Cells: A Pathway That Involves Cytokine Activation, Immunoglobulin Deposition, and Activation of Apoptosis. J J Am Heart Assoc. 2016; 5: e002484.

117. Adamo L, Staloch LJ, Rocha-Resende C, Matkovich SJ, Jiang W, Bajpai G et al. Modulation of subsets of cardiac B lymphocytes improves cardiac function after acute injury. JCI Insight. 2018; 3: 120137.

118. Choo $\mathrm{EH}$, Lee J, Park $\mathrm{E}$, Park HE, Jung $\mathrm{N}$, Kim $\mathrm{T}$ et al. Infarcted Myocardium-Primed Dendritic Cells Improve Remodeling and Cardiac Function After Myocardial Infarction by Modulating the Regulatory T Cell and Macrophage Polarization. Circulation. 2017; 135: 1444-1457.

119. Aghajanian H, Kimura T, Rurik JG, Hancock AS, Leibowitz MS, Li L et al. Targeting cardiac fibrosis with engineered T cells. Nature. 2019; 573: 430-433.

120. Elieh Ali Komi D, Wohrl S, Bielory L. Mast Cell Biology at Molecular Level: a Comprehensive Review. Clin Rev Allergy Immu. 2019; 58: 342-365.

121. Legere SA, Haidl ID, Legare J, Marshall JS. Mast Cells in Cardiac Fibrosis: New Insights Suggest Opportunities for Intervention. Front Immunol. 2019; 10: 580.

122. Levick SP, Melendez GC, Plante E, McLarty JL, Brower GL, Janicki JS. Cardiac mast cells: the centrepiece in adverse myocardial remodelling. Cardiovasc Res. 2011; 89: 12-19.

123. Ngkelo A, Richart A, Kirk JA, Bonnin P, Vilar J, Lemitre M et al. Mast cells regulate myofilament calcium sensitization and heart function after myocardial infarction. J Exp Med. 2016; 213: 1353-1374.

124. Luitel H, Sydykov A, Schymura Y, Mamazhakypov A, Janssen W, Pradhan K et al. Pressure overload leads to an increased accumulation and activity of mast cells in the right ventricle. Physiol Rep. 2017; 5: e13146.

125. Wei C, Hase N, Inoue Y, Bradley EW, Yahiro E, Li M et al. Mast cell chymase limits the cardiac efficacy of Ang I-converting enzyme inhibitor therapy in rodents. J Clin Invest. 2010; 120: 1229-1239.

126. Wang Y, Liu C, Fang W, Zhang X, Yang C, Li J et al. Deficiency of mouse mast cell protease 4 mitigates cardiac dysfunctions in mice after myocardium infarction. Biochim Biophys Acta Mol Basis Dis. 2019; 1865: 1170-1181.

127. Houde M, Schwertani A, Touil H, Desbiens L, Sarrhini O, Lecomte R et al. Mouse Mast Cell Protease 4 Deletion Protects Heart Function and Survival After Permanent Myocardial Infarction. Front Pharmacol. 2018; 9: 868.

128. Tejada T, Tan L, Torres RA, Calvert JW, Lambert JP, Zaidi M et al. IGF-1 degradation by mouse mast cell protease 4 promotes cell death and adverse cardiac remodeling days after a myocardial infarction. Proc Natl Acad Sci U S A. 2016; 113: 6949-6954.

129. Li J, Jubair S, Janicki JS. Estrogen Inhibits Mast Cell Chymase Release to Prevent Pressure Overload-Induced Adverse Cardiac Remodeling. Hypertension. 2015; 65: 191-328.

130. Wang H, Da Silva J, Alencar A, Zapata-Sudo G, Lin MR, Sun X et al. Mast Cell Inhibition Attenuates Cardiac Remodeling and Diastolic Dysfunction in Middle-aged, Ovariectomized Fischer 344 x Brown Norway Rats. J Cardiovasc Pharm. 2016; 68: 49-57.

131. Vagnozzi RJ, Sargent MA, Lin SJ, Palpant NJ, Murry CE, Molkentin JD. Genetic Lineage Tracing of Sca-1(+) Cells Reveals Endothelial but Not Myogenic Contribution to the Murine Heart. Circulation. 2018; 138: 2931-2939.

132. Vermeulen Z, Mateiu L, Dugaucquier L, De Keulenaer GW, Segers VFM. Cardiac endothelial cell transcriptome in neonatal, adult, and remodeling hearts. Physiol Genomics. 2019; 51: 186-196.

133. Varga I, Kyselovic J, Galfiova P, Danisovic L. The Non-cardiomyocyte Cells of the Heart. Their Possible Roles in Exercise-Induced Cardiac Regeneration and Remodeling. Adv Exp Med Biol. 2017; 999: 117-136. 
134. Gogiraju R, Bochenek ML, Schaefer K. Angiogenic Endothelial Cell Signaling in Cardiac Hypertrophy and Heart Failure. Front Cardiovasc Med. 2019; 6: 20.

135. Segers VFM, Brutsaert DL, De Keulenaer GW. Cardiac Remodeling: Endothelial Cells Have More to Say Than Just NO. Front Physiol. 2018; 9: 382.

136. Avolio E, Meloni M, Spencer HL, Riu F, Katare R, Mangialardi G et al. Combined Intramyocardial Delivery of Human Pericytes and Cardiac Stem Cells Additively Improves the Healing of Mouse Infarcted Hearts Through Stimulation of Vascular and Muscular Repair. Circ Res. 2015; 116: E81-E94.

137. Alvino VV, Fernandez-Jimenez R, Rodriguez-Arabaolaza I, Slater S, Mangialardi G, Avolio E et al. Transplantation of Allogeneic Pericytes Improves Myocardial Vascularization and Reduces Interstitial Fibrosis in a Swine Model of Reperfused Acute Myocardial Infarction. J Am Heart Assoc. 2018; 7: e006727.

138. Liu T, Wen $\mathrm{H}, \mathrm{Li} \mathrm{H}, \mathrm{Xu} \mathrm{H}$, Xiao N, Liu R et al. Oleic Acid Attenuates Ang II (Angiotensin II)-Induced Cardiac Remodeling by Inhibiting FGF23 (Fibroblast Growth Factor 23) Expression in Mice. Hypertension. 2020; 75: 680-692.

139. Morishige S, Takahashi-Yanaga F, Ishikane S, Arioka M, Igawa K, Kuroo A et al. 2,5-Dimethylcelecoxib prevents isoprenaline-induced cardiomyocyte hypertrophy and cardiac fibroblast activation by inhibiting Akt-mediated GSK-3 phosphorylation. Biochem Pharmacol. 2019; 168: 82-90.

140. Rizvi F, Siddiqui R, DeFranco A, Homar P, Emelyanova L, Holmuhamedov E et al. Simvastatin reduces TGF-beta 1-induced SMAD2/3-dependent human ventricular fibroblasts differentiation: Role of protein phosphatase activation. Int J Cardiol. 2018; 270: 228-236.

141. Milan M, Pace V, Maiullari F, Chirivi M, Baci D, Maiullari S et al. Givinostat reduces adverse cardiac remodeling through regulating fibroblasts activation. Cell Death Dis. 2018; 9: 108.

142. Lu W, Wang Q, Sun $\mathrm{X}, \mathrm{He} \mathrm{H}$, Wang $\mathrm{Q}, \mathrm{Wu} \mathrm{Y}$ et al. Qishen Granule Improved Cardiac Remodeling via Balancing M1 and M2 Macrophages. Front Pharmacol. 2019; 10: 1399.

143. Bejerano T, Etzion S, Elyagon S, Etzion Y, Cohen S. Nanoparticle Delivery of miRNA-21 Mimic to Cardiac Macrophages Improves Myocardial Remodeling after Myocardial Infarction. Nano Lett. 2018; 18: 5885-5891.

144. Abbaszadeh S, Javidmehr A, Askari B, Janssen P, Soraya H. Memantine, an NMDA receptor antagonist, attenuates cardiac remodeling, lipid peroxidation and neutrophil recruitment in heart failure: A cardioprotective agent? Biomed Pharmacother. 2018; 108: 1237-1243.

145. Ma X, Lin Q, Wang L, Xie X, Zhang Y, Li H. Rituximab prevents and reverses cardiac remodeling by depressing $B$ cell function in mice. Biomed Pharmacother. 2019; 114: 108804.

146. Wilhelmi T, Xu X, Tan X, Hulshoff MS, Maamari S, Sossalla S et al. Serelaxin alleviates cardiac fibrosis through inhibiting endothelial-to-mesenchymal transition via RXFP1. Theranostics. 2020; 10: 3905-3924.

147. Oduk Y, Zhu W, Kannappan R, Zhao M, Borovjagin AV, Oparil S et al. VEGF nanoparticles repair the heart after myocardial infarction. Am J Physiol Heart Circ Physiol. 2018; 314: H278-H284.

148. Rasanen M, Degerman J, Nissinen TA, Miinalainen I, Kerkela R, Siltanen A et al. VEGF-B gene therapy inhibits doxorubicin-induced cardiotoxicity by endothelial protection. Proc Natl Acad Sci U S A. 2016; 113: 13144-13149.

149. Zak MM, Gkontra P, Clemente C, Squadrito ML, Ferrarini A, Mota RA et al. Sequential Bone-Marrow Cell Delivery of VEGFA/S1P Improves Vascularization and Limits Adverse Cardiac Remodeling After Myocardial Infarction in Mice. Hum Gene Ther. 2019; 30: 893-905. 